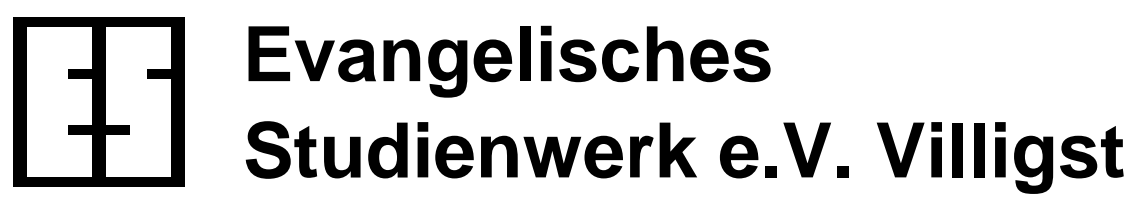
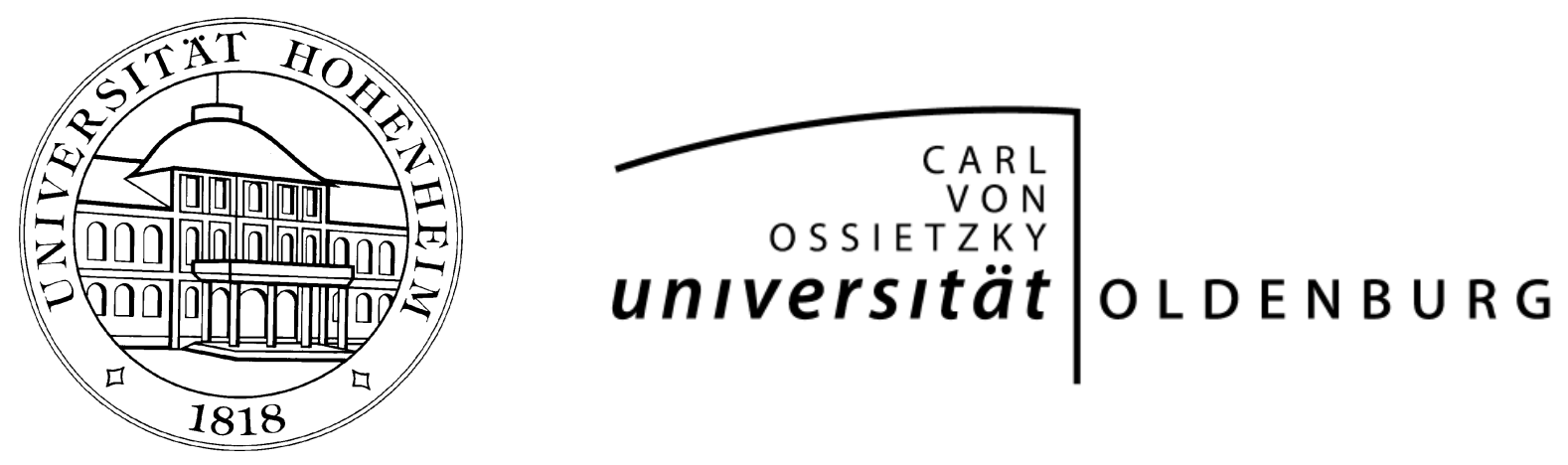

Schriftenreihe des Promotionsschwerpunkts

Globalisierung und Beschäftigung

Nr. 32/2010

Geographic Concentration and Spatial Inequality:

Two Decades of EPO Patenting at the Level of European Micro Regions

by

Julian P. Christ

Stuttgart-Hohenheim

ISSN 1618-5358 


\title{
Geographic Concentration and Spatial Inequality: Two Decades of EPO Patenting at the Level of European Micro Regions ${ }^{\dagger}$
}

\author{
Julian P. Christ*
}

April 2010

\begin{abstract}
This paper contributes with empirical findings to the research on structural inequality and geographic concentration of European inventorship activity at the level of European micro regions. We analyze the spatial structure and dynamics of 43 technology fields (ISI-SPRU-OST concordance) and 6 high-technology fields based on data on EPO patent applications and EPO inventors for the reference period 1977-2004. Based upon OECD RegPAT database (January 2009), we extract EPO patent applications (fractional counting) and inventor IDs (full counting), which are spatially linked to 819 European micro regions (OECD TL3), covering the EU-25, Switzerland and Norway. Besides standard descriptives, we compute Herfindahl-Hirschman indices, location quotients and weighted locational and spatial GINI coefficients. We confirm the hypotheses that (i) the technology fields under analysis differ in their overall size with respect to the stock of EPO patent applications and inventors; (ii) the share of regions with $L Q>1$ has decreased compared to the share of regions with at least a single patent application; (iii) the sample of European regions is characterized by highly concentrated and unequally distributed technology fields; (iv) spatial inequality of EPO patenting and inventor location has decreased significantly within the last two decades for most technology fields. In this respect, our quantitative approach clearly depicts dispersion tendencies and decreasing inequality, although structural dynamics differ between technology fields.
\end{abstract}

Keywords: geographic concentration, RegPAT, EPO patenting, GINI coefficient, location quotient, inventorship, inequality

JEL classification: C8, O31, O33, R12

$\dagger$ An earlier version of this paper (Oct 2009) was presented at the PhD workshops of the Research Center Innovation and Services (FZID CC I\&K), University of Hohenheim (17 Nov 2009; 8 Feb 2010). I thank Alexander Gerybadze, Harald Hagemann, Stan Metcalfe, Andreas Pyka, Ralf Rukwid, Jochen Streb and Andreas Wald for crucial comments.

*University of Hohenheim, Department of Economics, 70593 Stuttgart, Germany, mail: julian.christ $[a t]$ uni-hohenheim.de 


\section{Introduction}

The process of agglomeration and concentration was for a long time ignored and suppressed in economics; especially the role of spatial proximity for the process of spatial concentration of inventorship and innovation. Researchers have recently admitted the conceptual link existing between spatial convergence studies and agglomeration and concentration measures that can be regarded as its empirical counterpart (Krugman, 1992; Litzenberger, 2007; Brakman and van Marrewijk, 2008). ${ }^{1}$ Agglomeration and spatial concentration is nowadays increasingly challenged in economic theories (Rosenthal and Strange, 2003); furthermore the issues of divergence and spatial clustering are highly visible with the emergence of metropolises, industrial belts and urban areas all around the globe (Fujita and Krugman, 2003; Fujita and Mori, 2005). Hinloopen and van Marrewijk (2004) report an uneven distribution but regularity irrespective of the level of economic and regional aggregation or kind of activity. Similar results are reported by Brakman et al. (2005). Krugman (2001) already concludes:"Step back and ask, what is the most striking feature of the geography of economic activity? The short answer is surely concentration [...] production is remarkably concentrated in space." (Krugman, 2001, 5) In a similar fashion, Fujita, Krugman, and Venables (2001) mention the importance and rich value-added from incorporating the spatial dimension into economic theory and empirical research. They argue that "the defining issue of economic geography is the need to explain concentrations of population and of economic activity: the distinction between manufacturing belt and farm belt, the existence of cities, the role of industry clusters. Broadly speaking, all these concentrations form and survive because of some form of agglomeration economies, in which spatial concentration itself creates the favorable economic environment that supports further or continued concentration" (Fujita, Krugman, and Venables, 2001, 4). Once a core of economic activity has been established, be it a large city or an agglomerated region, its center increases size and economic importance by processes of self-reinforcement due to several centripetal (agglomerative) forces. Accordingly, economic clustering can be observed on many spatial levels: downtown areas of metropolises, formation of megalopolises, core-periphery structures within sub-national regions, agglomerations within larger countries, and additionally spatial concentration within federal unions (European Union, USA) (Fujita and Mori, 2005; Combes and Overman, 2004). As a consequence, spatial inequality and non-normal spatial distribution is a phenomenon that determines the structure of both, leading industrialized regions and regions in transition (e.g. CEEC, BRIC).

However, although industrial organization and production theories already found their place in geographical economics, the economic theories on inventorship and innovation were missing a spatial dimension for such a long time as it is the case with data driven, quantitative empirical studies (Audretsch and Feldman, 1996, 1999; Acs, Anselin, and Varga, 2002). In this respect, the majority of empirical findings on European inventorship location

$1 \quad$ see also Ellison and Glaeser (1997); Arbia (2001) 
structure is either based upon (i) anecdotal evidence, (ii) qualitative but not quantitative studies (case studies), (iii) small sample size due to data constraints, (iv) a-spatial concepts that are doomed to produce serious statistical biases, (v) convergence studies that ignore country size and regional heterogeneity, or (vi) biased samples of regions or countries that are not representative (Arbia, 2001; Brakman and van Marrewijk, 2008). With regard to the European case, several studies highlight that European countries converge in terms of GDP per capita, whereas European regions at the level of member states by and large do the opposite. This stylized fact seems to support the argument that regional level processes are much more complex (Arbia, 2001; Frenken and Hoekman, 2006; Paas and Schlitte, 2006). Although several studies analyzed the spatial dynamics of GDP and GVA, inventorship activity is still rather unexplored. With regard to the current empirical research frontier, our quantitative study thus tries to find empirical evidence for the following open research questions: (i) Is overall EPO patenting highly concentrated and thus unequally distributed across European micro regions? (ii) Do high-technology fields show an equal distribution across European micro regions or can we observe different patterns of spatial concentration and inventorship agglomeration by technology field? (iii) Is Europe determined by an increasing or decreasing share of specialized regions by means of location quotients? (iv) Do we observe convergence and dispersion within the last two decades or is Europe rather determined by a process of divergence and raising inequality in terms of EPO patenting?

The remainder of this paper is as follows: section 2 structures the empirical and theoretical background and reviews seminal empirical contributions. Section 3 describes the underlying database structure and the data extraction process from a regional and technological point of view. Section 4 reports our empirical research methodology. Section 5 highlights the empirical findings of our inequality study. Section 6 concludes.

\section{Background}

From a theoretical point of view, it is useful to distinguish four broad families of models in the existing theoretical literature when approaching spatial inequality analysis and convergence and divergence phenomena: (i) the traditional neoclassical approaches, (ii) models with external scale effects, spillovers and externalities, (iii) models with internal scale economies and market mediated linkages, and finally (iv) models that include (ii) and (iii) (Brülhart, 2001; Roos, 2002; Baldwin and Martin, 2004). From an empirical perspective, a strong motivation for analyzing the structure and dynamics of spatial inequality of European inventorship activity from relational patent data is based upon the fact that innovation data in general show a strong non-normal distribution and strong spatial autocorrelation, which is a severe issue for econometric modeling (Fotheringham, Brunsdon, and Charlton, 2002; Anselin, 2007). Several studies already pointed out the non-normal distribution of GDP per capita, gross value added (GVA) and employment across European regions (Paas and 
Schlitte, 2006; Frenken and Hoekman, 2006). Particularly high-tech industries and hightechnology fields are assigned to show strong tendencies to cluster in geographical space as empirically shown in national studies and regional innovation system analysis by e.g.Feldman (1994), Audretsch and Feldman (1996), Acs (2002) and Scherngell (2007). With regard to knowledge production and knowledge diffusion, geographical economics, economic geography proper and innovation system adherents have developed an established research tradition within the last years in studying the phenomenon of spatial clustering and agglomeration economies with respect to the benefits of geographical proximity for inventorship and innovation what is commonly labeled 'Marshallian externalities of the third kind': agents closely located to relevant knowledge stocks have potentialities in innovating faster than agents located far away, since neighboring units benefit from spatially bounded externalities. Several studies are conducted to showing that these externalities exist and that they can have a positive impact on innovation, per capita and employment growth (Usai, 2008). ${ }^{2}$ Therefore, we assume that the analysis of structural spatial inequality dynamics will help to understand the spatial structure of inventorship activity across European regions. In this respect, we are mainly interested in analyzing whether or not European regions show decreasing or increasing inequality in EPO patenting within the last two decades. This is of primary interest for recent debates on inventorship location, dispersion and growth.

However, one severe issue with empirical investigations of core-periphery structures and spatial dynamics is the question of aggregation from a sectoral and spatial perspective. Geographical economics always has the problem of defining and defending the relevant industrial and geographical scale of analysis (Audretsch and Feldman, 1996; Frenken and Hoekman, 2006). Ideally, real world industries and regions correspond to their theoretical counterparts. In practice, there is a tradeoff between industrial and regional detail. Some researchers choose three digit manufacturing industries which are available at the NUTS0 level (national level). Other researchers instead prefer a smaller level of one digit industries which are also available at a more detailed regional level. The geographical scope of the NEG literature is, according to Brakman et al. (2005), by and large restricted to levels of analysis at the NUTS2 and NUTS3, that is the level of districts and counties, and thus micro regions. The authors also suggest that "there is something to gain from sacrificing even more industrial detail for the sake of regional detail". (Brakman et al., 2005, 7). This paper directly follows this way of reasoning. ${ }^{3}$

Unfortunately, the availability of spatially disaggregated European data is disillusioning.

$2 \quad$ see also Bottazzi and Peri (2003), Moreno, Paci, and Usai (2005), Greunz (2005), Crescenzi, RodriguezPose, and Storper (2007), Hoekman, Frenken, and van Oort (2008), Ponds, Oort, and Frenken (2010)

3 Therefore, our study explores 43 technology fields based on EPO patent applications by priority date. Additionally, the paper also depicts structural dynamics of 6 large high-technology fields (laser, aviation, computers and automated business equipment, micro-organism and genetic engineering, communication technology and semiconductors). The patent classification system (IPC)-technology field concordance is applied to our own relational EPO patent database at the very disaggregated spatial level of OECD Territorial Level 3 (TL3) regions, which explicitly approaches the issue of functional spatial units. 
Combes and Overman (2004) complain: "After reviewing the literature, and given our first hand knowledge, the only conclusion that we are able to reach is that the European data are a mess. It is not clear where blame for this situation lies. It is clear that part of the problem stems from the institutional framework within which most EU governmental statistical agencies work. In particular, the fact that they often have no mandate to facilitate the re-use of data collected to fulfill their institution roles. Even where they do have a mandate, data are often expensive and incentives to ensure efficient delivery appear to be limited. [...] To summarise, the data situation is not good at the national, regional, or urban levels in the EU, although individual countries may provide excellent data sources." (Combes and Overman, 2004, 2847) Consequently, most studies are conceptualized at the national level (Amiti, 1999; Brülhart, 2001; Midelfart-Knarvik, Overman, and Venables, 2003; Aiginger and Pfaffermayr, 2004). In addition, the majority of contributions at the level of European regions center GDP and GVA distribution, employment and unemployment dynamics (Paas and Schlitte, 2006; Frenken and Hoekman, 2006). However most of these studies are mainly organized at the level of macro regions (Brakman and van Marrewijk, 2008; Brakman, Garretsen, and van Marrewijk, 2009) or restricted to single countries (Fornahl and Brenner, 2009). ${ }^{4}$ Finally, regional studies have to deal with several statistical issues like incomplete data coverage, selection biases, small sample size or inconsistent spatial and sectoral classification (Combes and Overman, 2004; Brulhart and Traeger, 2005).

Quite the contrary, patent data show several essential advantages. According to Griliches (1990, p. 1661), "[i]n this desert of data, patent statistics loom up as a mirage of wonderful plentitude and objectivity." No other STI-indicator can be traced back over such a comparatively long time period as patent applications or information of granted patents. Additionally, the information can be disaggregated to low spatial levels (cities, counties, provinces, districts); and perhaps most important, the information of inventorship can be allocated to individual economic units (inventors, firms). The information is also precise and accurate by means of an identification of the timing of the invention (priority application, priority date). However, there is also accepted criticism that patent data are only a very imperfect measure of innovative activities that have several limitations (Griliches, 1990). First, the range of patentable inventions constitutes only a subset of all possible R\&D outcomes. Second, technology fields vary tremendously in their patenting propensity due to structural differences. Third, patenting is in most cases a strategic decision of agents and thus not all inventions are actually patented even though inventions would satisfy the criteria for patentability. Fourth, many scientific advances devoid of immediate applicability and little incremental technological improvements might not be patentable. Despite all criticism, the analysis of information included in patent data is considered to be one of the most appropriate and established, directly available and historically reliable instruments for exploring inventorship activity and the dynamics of sectoral and regional innovation systems. Patent data are nowadays increas-

$\overline{4}$ Exceptions are Frenken and Hoekman (2006); Paas and Schlitte (2006). 
ingly used in order to measure the existence and spatial decay effects of knowledge spillover and other spatial externalities, e.g. Griliches (1979), Jaffe (1989) and Jaffe, Trajtenberg, and Henderson $(1993)^{5}$. Patent data are applied in order to measure spatial inequality of inventorship distribution (Audretsch and Feldman, 1996; Fornahl and Brenner, 2009). This is what we are approaching in this empirical study for a large sample of regions and countries.

Unfortunately, the statistical analysis of large European samples at the spatial level of counties and districts (functional micro-regions) represents, however, still a rather unexplored field of research. Therefore, the first objective of this paper is to provide a pure quantitative approach and systematic measurement of regional dispersion and inequality of inventorship activity over time and space at the level of European micro regions. ${ }^{6}$

\section{The Database}

In order to challenge our hypotheses and research questions, we apply a purely quantitative approach that makes use of data on EPO patent applications at the level of OECD TL3 micro regions. In this respect, the paper approaches spatial inequality of patent applications to the EPO for the reference period 1977-2004 by explicitly measuring the structural dynamics of patenting across 819 European regions for 43 technology fields and 6 high-tech fields. ${ }^{7}$ The analysis in this paper is based upon OECD RegPAT data, January 2009 version (Maraut, Dernis, Webb, Spiezia, and Guellec, 2008). The RegPAT files have been implemented into a workable mySQL database as presented in table 1 in order to generate relational data from patent information. Inventor locations are assigned to European counties and districts by inventor address as proposed by Maraut, Dernis, Webb, Spiezia, and Guellec (2008).

$<$ Table 1 about here $>$

The mySQL database is based upon EPO patent application data. This study is exclusively related to the distribution and structural dynamics of European inventorship activity

5 see also e.g. Griliches (1990), Griliches (1991), Acs (2002)

6 As we are explicitly interested in the spatial structure and distributional dynamics of inventorship activity across European micro regions, we do not address the issue of knowledge flows and spillover. Such complementary analysis can be found in, e.g. Crescenzi, Rodriguez-Pose, and Storper (2007), Usai (2008). Seminal contributions that address spatial lagging regressors and distance decay effects of innovative activity are e.g. Bottazzi and Peri (2003), Moreno, Paci, and Usai (2005), Greunz (2005). Moreover, we do not address inventorship or co-inventorship network structures or patent citation flows. An established research approach for depicting and analyzing innovation networks and knowledge flows is to use patent citation data. This method is well-known in empirical analysis, especially for approaching knowledge spillover and inventor linkages as an alternative to knowledge production function estimations (Thompson and Fox-Kean, 2005; Scherngell, 2007). Breschi and Lissoni (2009) argue that "the most fundamental reason why geography matters in constraining the diffusion of knowledge is that mobile researchers are not likely to relocate in space, so that their co-invention network is also localized." (Breschi and Lissoni, 2009, 1) Studies in this respect are Kroll (2009), Ponds, Oort, and Frenken (2010), Christ (2009), Miguelez and Moreno (2010).

7 The paper uses full time series instead of random years because the latter might not be representative for the overall evolution of inequality in EPO patenting. 
across European micro regions, which consequentially prefers EPO to PCT (triadic) patent applications, due to an explicitly defined macro level. Thus, the European sample of 819 micro regions should minimize potential spatial bias. ${ }^{8}$ The inequality measures are accomplished by calculating location quotients from patent intensity indices (patents per million population) and patent densities (patents per square kilometer). Population data have been collected according to the established NUTS2003 classification for the reference period 1988 until 2005 at the NUTS3 level; in a second step, the data are aggregated to functional regions according to the OECD TL3 classification. ${ }^{9}$ Table 2 summarizes the spatial structure of our sample. ${ }^{10}$

\section{$<$ Table 2 about here $>$}

We restrict our analysis to the reference period 1977-2004 (1988-2004 for population corrected inequality measures). The agents are in general inventors, whose postal address, which is their work place location, can be used to determine their location in geographical space. Based on inventor address information, patent applications are assigned to micro regions (here OECD TL3 units) by fractional counting. Fractional counting means that each inventor located in a certain region gets an identical fraction of what ended with a patent application to the EPO within the reference period. Accordingly, if a patent has e.g. three inventors from three different spatial units, each spatial unit gets a share of one third. In this respect, the 819 micro regions add up to 904.917,129 EPO patent applications (fractional counting by priority date) and 1.616.257 inventor IDs (full counting by priority date) within the reference period 1977-2004.

However, a serious problem in geographical economics and the geography of innovation literature is the definition and usage of spatial units. We need at least two entities that are in general called a place, a region or county. However, the difficulty with this concept is rather unnoticed and it seems that people have to suffer from the same theoretical vagueness with the 'concept of the region' as with the 'concept of the industry', which essentially depends on statistical classifications. Both concepts resemble some intermediate and flexible levels of aggregation and are thus not easy to define. The aggregation of places to a certain region depends essentially and ultimately on the underlying research question and empirical application; the selection of borders mainly depends on the existence of spatial dependence, what could be a indication for functional regions. Accordingly, the aggregation issue is highly fuzzy and crucial in applied research. The OECD Territorial Level 3 classification (TL3) could

$8 \quad$ European regions have a higher propensity to protect new knowledge in terms of EPO patent applications.

9 The results do not differ much from the recently introduced NUTS2006 classification. Unbelievably, EUROSTAT demolished all GDP and population data at the NUTS3 level according to the antecedent NUTS2003 classification. Several official data requests have been disappointing. I want to thank Jarno Hoekman (Utrecht) and Sven Wydra (Fraunhofer ISI) for their help with population data.

10 Bulgaria (BG), Croatia (CR), Liechtenstein (LI) and Romania (RO) are not include in the subsequent analysis due to data issues. 
be roughly interpreted as more homogenous labor market regions. Admittedly, the usage of TL3 units simplifies the issue of functional spatial boundaries of regional systems. ${ }^{11}$ However, the TL3 level is the most detailed and statistically useful regionalization level available for OECD countries and European member states. Thus, the underlying relational database extraction in this paper thus focuses on 819 (EU25+CH+NO) TL3 units as highlighted in table $2 .{ }^{12}$

From a technology field point of view, aggregation and matching of the International Patent Classification (IPC) and the technology field classification is accomplished in this project by application of the ISI-SPRU-OST-concordance (Fraunhofer ISI, Karlsruhe, Germany, Observatoire des Sciences et des Techniques (OST), Paris, France and SPRU, University of Sussex, Brighton, UK) of Schmoch, Laville, Patel, and Frietsch (2003). Additionally, we analyze six established high-technology fields according to the EUROSTAT (2009) concordance for the whole reference period and sample size (table 3$).{ }^{13}$

\section{$<$ Table 3 about here $>$}

Patents are linked to technology fields in terms of full counting. If the patent document contains several IPC codes we apply unique counting. Thus, if a patent application contains five different IPC codes, which represent (are included in) five different technology fields at the same time, the patent is added to each of these five fields in terms of unique but full

11 The extracted patent data from OECD RegPAT database (January 2009) are regionalized according to the NUTS2003 classification (Maraut et al., 2008) to 1259 NUTS3 regions; afterwards, they are aggregated according to the OECD TL3 classification to micro regions. We simplify by interpreting TL3 units as counties or districts with functional boundaries, although the regional size of the units vary to some extent. We therefore take TL3 units as the general geographical classification concept, which also simplifies comparison with other studies and is much more related to functional units.

12 We aggregate the 439 "Stadt-/Landkreise" in Germany (NUTS3) to 97 so called "Raumordnungsregionen" (planning regions), Dutch and Belgian NUTS3 units to the NUTS2 level (which is OECD TL3). Similarly, we aggregate Greek islands and small units to Greek NUTS2 units and solve several issues: (i) Several NUTS3 units are relatively small and numerous in comparison with other EU NUTS3 units. The application of e.g. 439 German NUTS3 regions would increase the influence of German regions in the analysis significantly. (ii) Additionally, when using NUTS3 patent data, the existence of relatively small regional units may induce the issue of commuting of inventors between their place of residence and place of work and thus mean location bias. The whole sample of 819 TL3 units is formed by 774 TL3 micro regions of the EU25 member states, Norway (19 TL3) and Switzerland (26 TL3). 651 units belong to the EU-15 and 123 belong to the CEEC. We include Switzerland and Norway to avoid black holes in the spatial structure. However, we exclude new or potential member states, e.g. Croatia (HR), Romania (RO) and Liechtenstein (LI), due to data constraints.

13 The IPC system (IPC revision 8.0) is an internationally agreed, non-overlapping hierarchical classification system that consists of eight sections (first level), 118 classes (second level), 628 subclasses (third level), 6.871 (fourth level) main groups and 57.324 subgroups (fifth level) to classify inventions claimed in the patent documents. The IPC divides patentable technology into eight key areas; A: Human Necessities; B: Performing Operations, Transporting; C: Chemistry, Metallurgy; D: Textiles, Paper; E: Fixed Constructions; F: Mechanical Engineering, Lighting, Heating, Weapons; G: Physics; H: Electricity. Within these areas technology is divided and subdivided to a detailed level, which allows the subject matter of a patent specification to be very thoroughly classified. Although there exist alternative concordance tables for aggregating and matching patent classes with industries (Evenson et al., 1991; Verspagen et al., 1994), the ISI-SPRU-OST concordance represents one of the most recent approaches to this issue (Schmoch, Laville, Patel, and Frietsch, 2003). 
counting. Additionally, if a patent application contains several IPC codes which represent only one technology field, the patent is uniquely linked to the technology field by the first corresponding IPC code (unique counting). ${ }^{14}$

\section{Measuring Spatial Inequality and Geographic Con- centration}

The most common way to analyze and assess the applicability of inequality coefficients is by comparing the behavior of such indices with respect to several axioms that are theoretically derived as preferable properties of such measures: (i) anonymity (no personal characteristics other than the income determine the ordering principle), (ii) scale independence or income homogeneity (multiplying all incomes with the same positive scalar does not change inequality), (iii) population independence or population homogeneity (replicating every income an integral number of times does not change inequality), (iv) the transfer principle or Pigou-Dalton condition (transfers from a richer to a poorer person do reduce the measured inequality). Only a few measures can satisfy these axioms: the coefficient of variation, the GINI coefficient, the Atkinson class of measures, and the generalized entropy family of measures, with the Theil index being the most prominent example (Kim, 1995; Gallagher, 2008; Jenkins and Kerm, 2009). An objection against the GINI is the difficulty of subgroup decomposition and subgroup consistency. ${ }^{15}$ Additionally, the GINI index measures the same inequality of economic activity, irrespective of the true spatial location of observations (neighbors or not), meaning that spatial dependence and thus spatial autocorrelation cannot be identified (Arbia, 2001; Anselin, 2007; Christ, 2009). However, given the wide popularity and the otherwise favorable properties of the GINI index, it will be applied in this study as the central measure for total (global) inequality. Thus, we compute different GINI alternatives at the aggregated European level with micro regions being our observations. Another important aspect is the differentiation between concentration and specialization. Concentration is assessed in a similar manner compared to specialization. The sole difference to specialization measures is that instead of a comparison of industrial structures within a single region, concentration measures involve a comparison of regions' industrial structures across all regions involved (Hoover, 1936; Ellison and Glaeser, 1997; Krugman, 1992; Amiti, 1999; Arbia, 2001; Jenkins and Kerm, 2009). Absolute specialization means that a small

14 If a patent document corresponds to several technology fields in terms of included IPC codes, the patent is uniquely linked to each technology field by factor one, multiplied with the fractional share of the local inventor. Thus, patents with many IPC codes have a higher propensity to be linked to more than one technology field.

15 This is an essential problem for EU-wide studies at the regional level that try to depict within- and between country differences in geographical distribution and inequality. Global inequality can result from nation-specific distribution characteristics, but also from significant differences between countries (Brulhart and Traeger, 2005; Duro, 2004; Paas and Schlitte, 2006). 
share of industries account for a large share of economic activity of a region under analysis. In contrast, absolute concentration is about whether a few regions tend to account for a large share of economic activity of an industry. However, a much more complex analysis is the distributional measure with respect to all industries, technology fields or regions. The corresponding types of concentration and specialization are then measured in relative terms (related to a reference region or industry). From an empirical point of view, some country studies at the national level tend to measure an increasing concentration and specialization of economic activity. In contrast, some regional studies at the level of the US MSA or European NUTS units tend to make the opposite. Moreover, specialization and concentration seem diverging, 'even though they conceptually are each other's mirror image' (Brakman et al., 2005, 29). ${ }^{16}$ It should be noted that the studies by and large differ with respect to aggregation levels and spatial classification schemes what essentially determines the results.

First, we compute the features of the distributions of EPO patent applications and EPO inventors by technology field. Therefore, kurtosis and skewness are two statistical instruments for analyzing the distributional characteristics. Skewness and kurtosis show how the distribution of a variable deviates from a normal distribution. Skewness is the third standardized moment that measures the degree of symmetry of a probability distribution as presented in equation 1.

$$
\nu=\frac{m^{3}(\mu)}{\sigma^{3}}=\frac{n}{(n-1)(n-2)} \sum\left(\frac{x_{i}-\bar{x}}{s}\right)^{3}
$$

If skewness is greater than zero, the distribution is skewed to the right, having more observations on the left. $m^{3}(\mu)$ is the third central moment and $\sigma$ is the standard deviation. Kurtosis, on the other hand, is based on the fourth central moment, measuring the thinness of tails or peakedness of a probability distribution as presented in equation 2 .

$$
\xi=\frac{m^{4}(\mu)}{\sigma^{4}}-3=\left[\frac{n(n+1)}{(n-1)(n-2)(n-3)} \sum\left(\frac{x_{i}-\bar{x}}{s}\right)^{4}\right]-\frac{3(n-1)^{2}}{(n-2)(n-3)}
$$

with $m^{4}(\mu)$ being the fourth central moment. If the kurtosis parameter value of a random variable is less than three (or negative), the distribution has thicker tails and a lower peak compared to a normal distribution. By contrast, a kurtosis parameter value larger than three indicates a higher peak and thin tails. A normally distributed random variable should have skewness and kurtosis near zero (between zero and three respectively).

Second, we make use of a simple Herfindahl-Hirschman-Index (HHI) that measures spatial concentration of inventorship activity across 819 micro regions. Therefore, the HHI places the number of EPO patent applications $x_{i j}$ of a region $j$ in a technology field $i$ in relation to the patent application number of the aggregate $\sum_{j} x_{i j}$, what represents the regional share

16 see also Kim (1995); Knarvik and Steen (1999); Keilbach (2000); Combes and Overman (2004); Fornahl and Brenner (2009). 
$x_{i j} / \sum_{j} x_{i j}$ of region $j$ in technology field $i$. Summing up $x_{i j} / \sum_{j} x_{i j}$ and taking the root then forms the HHI for each technology field $i$ (equation 3). ${ }^{17}$

$$
H H I_{i}=\left[\sqrt[\alpha-1]{\sum_{j}\left(x_{i j} / \sum_{j} x_{i j}\right)^{\alpha}}\right]
$$

Third, we compute the location quotient (LQ) that is an influential measure of spatial specialization as illustrated in equation 4 (Hoover, 1936; Amiti, 1999; Litzenberger, 2007; Gallagher, 2008; Jenkins and Kerm, 2009). The $L Q_{i j}$ expresses importance of an industry or technology field $i$ under analysis, based on its relative share in the local or national economy. The $L Q_{i j}$ for an industry or technology field $i$ in region $j$ is then calculated as presented in equation $4 .{ }^{18}$

$$
L Q_{i j}=\left[x_{i j} / \sum_{j} x_{i j}\right] /\left[\sum_{i} x_{i j} / \sum_{i} \sum_{j} x_{i j}\right]
$$

with $x_{i j}$ being activity in industry or technology field $i$ in region $j ; \sum_{j} x_{i j}$ is the activity in industry or technology field $i$ in the spatial aggregate of regions $j ; \sum_{i} \sum_{j} x_{i j}$ is total economic activity in the aggregate of regions and $\sum_{i} x_{i j}$ is total regional economic activity (all technology fields) in region $j$. Rearranging equation 4 leads to the classical relative specialization index. Thus, a location quotient $L Q_{i j}<1$ means that the economic activity in the industry or technology field is less present in the region under observation compared to the reference region (higher spatial aggregate). In contrast, $L Q_{i j}>1$ illustrates a relative higher share of industry or technology field activity compared to the aggregate of regions (reference region). Alternatively, $L Q_{i j}$ is sometimes expressed as the Balassa- or HooverBalassa index. Studies of international trade mostly refer to the Balassa index, whereas the label location quotient is traditionally widely used in regional science and geographical economics (Krugman, 1992; Litzenberger, 2007; Gallagher, 2008). The LQ-measure is one of relative specialization as it measures the spatial fraction of an industry or technology field in one region in comparison to the fraction of the aggregate of regions in the sample. Consequently, the indicator does not say anything about the absolute size of an industry or area (no scale component included). Thus, it is possible to obtain a high LQ for small spatial units in the sample. ${ }^{19}$ However, we are explicitly interested in using EPO patent data due

$\overline{17}$ It must be noted that HHI is sensitive to $\alpha$ with $\alpha=2$ being the standard HHI parameter value. Thus, the sensitivity of the HHI measure increases with $\alpha$. The HHI reports total inequality, if one single region holds all patent applications; in contrast, the HHI shows equal distribution, if all regions hold $1 / 819$

18 Appropriate and commonly applied variables for this measure are industry employment, production and plant level data. It is essential to note that the coefficient can also be used for alternative STI data analyses, such as R\&D employment and product innovations. In the end, however, the only trustable and direct measure for inventorship location patterns are patent applications.

19 An easy way to make use of the Balassa index as an agglomeration index and indicator of spatial 
to our research purpose and modify equation 4 into 5 :

$$
L Q_{i j}=\left[x_{i j} / \sum_{j} x_{i j}\right] /\left[n_{j} / \sum_{j} n_{j}\right]=s_{i j} / y_{j}
$$

It is worth noting that we apply a comparison of the shares of EPO patent applications $s_{i j}$ of regions $j$ by technology field $i$ and the spatial shares of population $y_{j}$, which differs from the conventional Krugman approach (Krugman, 1991). In this respect, we first have to calculate the regional share of EPO patent applications $s_{i j}$ of each OECD TL3 region for a predefined sample of 51 technology field aggregates (Schmoch et al., 2003). Second, we compare these shares with the population shares $y_{j}$ of all observations and compute location quotients for 819 OECD TL3 regions, which represents the sort criterion for our GINI computations with $L Q_{i 1}<L Q_{i 2}<\ldots<L Q_{i n} \cdot{ }^{20}$

Fourth, the obtained LQs are used for calculating locational and spatial GINI coefficients for inequality analysis. ${ }^{21}$ Generally, the GINI coefficient is a measure of statistical dispersion. The traditional methodology commonly uses the coefficient as a measure of inequality of income or wealth (Litzenberger, 2007; Gallagher, 2008; Jenkins and van Kerm, 2009). The coefficient normally compares income distribution with population distribution at the micro level (households, workers, other individuals). The concept uses pairwise comparison of all observations. The standard GINI, $G_{S T}$, is then a normalization (division by 2 ) of the relative mean difference from the arithmetic mean of all observation pairs (interval $[0,1]$ ). The GINI coefficient is usually defined mathematically based on the Lorenz curve concept. It can be thought of as the ratio of the area that lies between the line of equality and the Lorenz curve over the total area under the line of equality. Low GINI coefficients indicate a more equal distribution, with $G_{S T}=0$ corresponding to complete equality; the bisecting line in the graph then corresponds to the Lorenz curve; however, higher GINI coefficients indicate a more unequal distribution, with $G_{S T}=1$ corresponding to complete inequality (maximum concentration surface $C$ ). To be computed validly, no negative goods/income can be distributed. Thus, if the GINI coefficient is being used to describe household income inequality (which is the common empirical case in most studies), then no household can have a negative income. ${ }^{22}$. In our case, economic activity of regions is unequally distributed when the largest share of activity is located in only a few regions (still homogeneous observations). We can also think of technology fields or industries being spatially concentrated if the majority of specific activities takes place in only a few regions, compared to the superior distribution

distribution is to calculate the standard deviation of LQ for each technology field or industry under analysis across cities, counties, districts or regions.

20 This calculation is identical to calculations that make use of calculated patent intensities (LQ with the absolute number of patents in the numerator and the absolute number of population in the denumerator).

21 I thank Ralf Rukwid for fruitful discussions and crucial feedback concerning spatial GINI computation.

22 In case of patent applications, some observations can have zero values as patenting is highly concentrated; thus, we apply a modified GINI calculation. 
(unweighted observations), which means that both distributions can vary tremendously as shown by the deviation of the Lorenz curve from the bisecting line (45-degree line). More generally, the GINI coefficient relates the distribution of a selected economic activity $\xi$ to an average or superior distribution of another variable $\zeta$ that is the reference distribution. The standard GINI measure is calculated according to equation 6 , with $n$ being the number of regions in the sample, $x$ being the parameter value of region $i$ and $j$, and $\mu$ being the mean of the parameter value $x$.

$$
G_{S T}=\frac{C}{1 / 2}=2 C=\left[\frac{1}{2 \mu n^{2}} \sum_{i=1}^{n} \sum_{j=1}^{n}\left|x_{i}-x_{j}\right|\right]
$$

In case of a discrete feature distribution, the maximum concentration surface is not $1 / 2$ but $1 / 2-1 / 2 \times 1 / n)$. Thus, the normalization of $G_{S T}$ into $G_{S T}^{*}$ allows the comparison of differing sample size; in our case different technology fields and numbers of regions, as presented in equation $7 .{ }^{23}$

$$
G_{S T}^{*}=\left[\frac{1}{2 \mu n(n-1)} \sum_{i=1}^{n} \sum_{j=1}^{n}\left|x_{i}-x_{j}\right|\right]
$$

For a large sample size, the $G_{S T}$ reaches 1 only asymptotically with $0 \leq G_{S T} \leq 1-1 / n$. Normalization of $G_{S T}$ into $G_{S T}^{*}$ for $[0,1]$ is then accomplished by division of $G_{S T}$ with $1 / 2 \times$ $(1-1 / n)$ which guarantees $0 \leq G^{*} \leq 1$ (Litzenberger, 2007; Gallagher, 2008). However, note that $(1-1 / n)$ only normalizes for observations that have identical weights. ${ }^{24}$

With respect to the homogeneity issue, $G_{S T}^{*}$ has to be modified in order to account for heterogeneity of observations. From a methodological point of view, in the case of spatial dispersion of industry or inventorship activity, we can think of several modifications of $G_{S T}^{*}$. In the case of spatial analysis, $G_{S T}^{*}$ would take regions or locations as $n$ identically weighted observations and the number of firms, employees or patents of these spatial unit as relevant parameter values. The obtained $G_{S T}^{*}$ coefficient would then measure inequality of economic activity across spatial units without explicitly weighting subspaces, meaning that each region holds an identical fraction of the reference distribution (identical in GVA, employment, population). However, we think that this approach is highly misleading and distorts our inequality measure. In this respect, $G_{S T}^{*}$ is only an adequate index in measuring the industry specific concentration with respect to the number of observations, but not their heterogeneity by means of areal size or population characteristics, which contradicts reality (Litzenberger, 2007; Gallagher, 2008; Fornahl and Brenner, 2009). As a result, GINI computations at the level of regions have to include explicit weights for the treatment of spatial heterogeneity,

23 Additionally, when the number of regions $j$ is potentially smaller than the number of technology fields $i$, we could correct the GINI calculation with $(1-j) / i$.

$24 G_{S T}^{*}$ computation assumes that $n$ observations are homogeneous. 
which supports the application of weighted GINI coefficients. In this respect, Krugman (1992) utilizes a locational GINI coefficient which does not take the absolute number of employees in an industry or sector into account but its regional share of employment of the subspace in the industry $i$; therefore, Krugman computes the location quotients, which represent the sort criterion for further GINI calculations (Krugman, 1992; Audretsch and Feldman, 1996). Related to this methodology, we first have to calculate the regional share of economic activity in the technology field $i$ for every subspace $j$, but also the share of total economic activity of the spatial units, which is $\sum_{i} x_{i j} / \sum_{i} \sum_{j} x_{i j}$. The relation of both shares is again $L Q_{i j}$, which measures relative technology field occupancy of subspaces $j$ (Gallagher, 2008). However, the locational GINI approach of Krugman measures employment specialization of a subspace in relation to a higher spatial aggregate. Thus, Krugman and colleagues are comparing the distribution of industry specific employment with the distribution of total employment, which rather corresponds to an index of specialization but not concentration. In this respect, we prefer to modify their approach in computing an alternative LQ as presented in 5 (Gallagher, 2008). This means that we compute LQs for each subspace with $L Q_{i j}=\left[s_{i j} / y_{j}\right]$ with $s_{i j}$ being the patent application share in technology field $i$ of region $j$ and $y_{j}$ being the population share of the region as presented in equation 8. ${ }^{25}$ Equation 8 represents our standard locational GINI approach.

$$
G_{L O C}=2\left[\frac{1}{2}-\frac{1}{2} \sum_{j=1}^{n} y_{j}\left(s_{i j}+2 \sum_{k=j+1}^{n} s_{i k}\right)\right]
$$

Equation 8 can be rearranged into 9:

$$
G_{L O C}=2\left[\frac{1}{2}-\left[\sum_{j=1}^{n}\left(\frac{1}{2} y_{j} s_{i j}\right)+\sum_{j=1}^{n}\left(x_{j} \sum_{k=j+1}^{n} s_{i k}\right)\right]\right]
$$

$G_{L O C}$ coefficient is a population weighted GINI in terms of $y_{j}$, which also needs modifications of the formerly described normalization procedure. Normalization of $G_{L O C}$ into $G_{L O C}^{*}$ is here accomplished by correcting for the minimum populated region with miny $y_{j}$ what guarantees a maximum concentration surface as presented in equation 10. In case that the share of economic activity of a technology field $s_{i j}$ across subspaces $j$ is identical to the share of total economic activity $\sum_{i} x_{i j}$ (e.g. total employment) or another reference distribution $y_{j}$, we would compute a location quotient $L Q_{i j}=1$ for every region, and thus a locational GINI coefficient $G_{L O C}^{*}=0$. The Lorenz Curve is then identical to the bisecting line. However, the more the distribution of the industry or technology field $s_{i}$ differs from the reference distribution, the more the location quotient differs from 1 and the larger is $G_{L O C}^{*}$. In this respect, our $G_{L O C}^{*}$ coefficient takes $s_{i j}$ and $y_{j}$ for each region and computes the cumulated

$\overline{25} \quad$ It should be noted that the obtained GINI from $L Q_{i j}$ is identical to usage of patent intensity of region $j$ divided by the patent intensity of the aggregate of regions $\sum_{j}$. Relative technology field occupancy and $L Q_{i j}$ are then formally the same. 
sum of patent application shares of all subspaces, ordered by the regional location quotient. Hence, our modified $G_{L O C}^{*}$ coefficient, also applied in similar ways by Kim (1995), Litzenberger (2007) and Gallagher (2008), resembles a concentration index that explicitly measures pure concentration in space.

$$
G_{L O C}^{*}=\left[2\left[\frac{1}{2}-\left[\sum_{j=1}^{n}\left(\frac{1}{2} y_{j} s_{i j}\right)+\sum_{j=1}^{n}\left(y_{j} \sum_{k=j+1}^{n} s_{i k}\right)\right]\right]\right]\left[\frac{1}{1-\text { miny }_{j}}\right]
$$

For comparison purpose, we have also computed an alternative GINI coefficient $G_{S P A C E}$, which controls for spatial unit size by means of areal surface data. Consequently, the spatial density of economic activity under analysis comes directly to the fore (Roos, 2002; Litzenberger, 2007; Gallagher, 2008). We interpret areal size as being the "true and only" geography control variable that controls for spatial density and thus for concentration of economic activity across European regions. Accordingly, the normalized spatial GINI coefficient $G_{S P A C E}^{*}$ compares the distribution of inventorship activity $s_{i j}$ of region $j$ in a technology field $i$ with the distribution of areal size $z_{j}$ (square kilometers), corrected for maximum concentration; this is identical to equation 10 , except $z_{j}$.

$$
G_{S P A C E}^{*}=\left[2\left[\frac{1}{2}-\left[\sum_{j=1}^{n}\left(\frac{1}{2} z_{j} s_{i j}\right)+\sum_{j=1}^{n}\left(z_{j} \sum_{k=j+1}^{n} s_{i k}\right)\right]\right]\right]\left[\frac{1}{1-m i n z_{j}}\right]
$$

In the case of inventorship analysis by means of EPO patenting, we take the regional share of EPO patent applications of subspaces $s_{i j}$ in a predefined set of 51 technology fields and compare these shares with the share of subspaces in areal surface $z_{j}$, which represents our sort criterion. $I D_{i j}>1$ means that region $j$ differs positively from its areal surface share $z_{j}$. In opposition, $I D_{i j}<1$ means that the region under analysis has a much smaller patent density. In this respect, $I D_{i j}$ is our sort sequence parameter value for the $G_{S P A C E}^{*}$ computation with $I D_{i 1}<I D_{i 2}<\ldots<I D_{i n}$. Normalization into $G_{S P A C E}^{*}$ is done identically as for $G_{L O C}^{*}$ by correcting for the smallest spatial unit, here in terms of square kilometers, what maximizes the potential concentration surface $C$. Samples that are defined by huge differences in areal surface, although population shares being more or less equally distributed, potentially produce smaller $G_{S P A C E}^{*}$ parameter values compared to $G_{L O C}^{*}$. Moreover, it is essential to note that aggregation could induce the so called modifiable areal unit problem (MAUP), which means that the GINI coefficient (and other indices) can vary due to aggregation of surface or population. ${ }^{26}$ Small areal units tend to show large variation due to core-periphery

26 The problem is that geographical phenomena cannot be measured at a single point but only within a predefined spatial area. The MAUP is intrinsic to the measure; it is a phenomenon that has a geographical dimension and can be decomposed into two interrelated effects: (i) a zonation effect and (ii) a scale effect. The scale effect is the variation in numerical results due to the number of zones. The zonation effect is then the variation of statistical results due to aggregation of spatial units to districts, regions or countries. 
issues of e.g. population differences; thus shares and intensities vary tremendously. On the contrary, larger areal units tend to produce much more stable numerical results (averaging process). However, meaningful geographic variation in EPO patenting- and that is what we explicitly want to explore - could be lost due to aggregation to a higher spatial level. Accordingly, we prefer sacrificing technology field details in favor of spatial details.

\section{$5 \quad$ Empirical Results}

The tables 4 and 5 summarize the descriptive statistics for EPO patent applications and EPO inventors by technology field. ${ }^{27}$ Besides the standard descriptives, we report a Herfindahl-Hirschman index (HHI) that measures spatial concentration by technology field; moreover, we compute the \%change of HHI from 1990-1992 to 2002-2004. ${ }^{28}$ It is definitely visible that most technology fields are determined by decreasing HHI values for EPO patent applications and EPO inventors, which causes decreasing geographic concentration across all 819 TL3 regions. Similarly, the following tables with respect to \%changes of regions with $n>0$ EPO patent applications and $n>1$ EPO inventors underline these results. ${ }^{29}$

$<$ Tables 4 and 5 about here $>$

Second, we focus on the regional structure of EPO patent applications and EPO inventors at the level of technology fields. It is worth noting that almost each technology field within our sample is determined by only a small fraction of European micro regions that have at least one EPO patent application at the early stage of the reference period as illustrated in figure 1. However, almost 50 per cent of all 819 regions remain without a single patent application (fractional counting) in 32 technology fields, even in the year 2004, which supports our hypothesis that inventorship activity is highly concentrated across the sample of 819 micro regions. However, we observe significant dispersion tendencies of EPO patent applications across European micro regions, although the technology fields widely differ in their structural dynamics.

$<$ Figure 1 about here $>$

With respect to individual technology fields, the lowest dispersion tendencies in terms of regions with at least one single EPO patent application across the sample can be observed for the following technology fields: TF12: paints \& varnishes, TF41: watches \& clocks, TF2: tobacco products, HT4: laser, TF16: man-made fibres, TF5: leather articles, TF4: wearing

27 minimum (min nb), maximum (max nb), mean (mean $\mathrm{nb}$ ) and total numbers (tot $\mathrm{nb}$ ), regional maximum share (max reg share), kurtosis (kurt), skewness (skew), 30\% and 70\% percentiles (P30, P70)

28 However, HHI is not weighted by population or region size; thus, the standard HHI measure takes regions as homogeneous units.

29 It is worth noting that $294.980 \mathrm{EPO}$ inventors (18,25\% of all registered inventors) are linked to hightechnology patent applications for the period 1977-2004. 
apparel, TF26: weapons \& ammunition, TF6: wood products and HT1: aviation. These technology fields are characterized by (i) a rather small amount of patent applications and (perhaps) (ii) a small propensity to patent (however note that (ii) is not the main research question of this study). Thus, we have to assume that these two properties significantly affect inequality measures. ${ }^{30}$

In opposition to these highly concentrated technology fields, we observe disperse spatial structures for the following technology fields: TF21: energy machinery, TF35: signal transmission \& telecommunications, TF28: office machinery \& computers, TF38: measuring instruments, TF42: motor vehicles, TF22: non-specific purpose machinery, TF37: medical equipment, TF17: rubber \& plastic products, TF25: special purpose machinery, TF13: pharmaceuticals and TF10: basic chemical. These fields are characterized by (i) larger shares of regions within the sample that keep at least one single patent application and thus a higher dispersion across the 819 TL3 units, (ii) a larger number of IPC codes that form the technology field, (iii) a larger number of EPO patent applications, and (iv) potentially higher propensities to file patents at the EPO (again, (iv) is not the main research question of this paper).

Another extraction shows that only a few of the regions contribute with larger fractions of overall patenting, although several regions contribute to EPO patent applications in the technology fields under analysis. Figure 2 highlights the computed share of regions within the sample of EU regions that have $\mathrm{n}>9$ EPO patent applications. A similar result is plotted in figure 3, which visualizes the share of regions that have at least 10 inventors (heterogenous inventor IDs) by technology field. The larger the fraction of regions that correspond to this category, the more the technology field appears to be dispersed across the 819 micro regions; additionally, these micro regions can be thought of as being clusters of inventors and thus innovation clusters. The figures 2 and 3 clearly depict that (i) several technology fields are highly concentrated in space and (ii) that the utilization of inventorIDs also represents an admissible proxy for patent applications in cluster and location studies. ${ }^{31}$

$<$ Figures 2 and 3 about here $>$

The previous computations only account for the absolute number of EPO patents and hence for absolute specialization (scale component). As a result, we cannot say anything about relative specialization or concentration of regions. Therefore, we make use of alternative

30 It is clear that the market structure can have effects on the dispersion measures; industries and thus technology fields that consist of a small number of firms tend to be relatively more concentrated in space; although we make use of inventor location information, inventors also cluster around the applicant location.

31 Note that the fractions reported in figures 2 and 3 can differ, because we applied full counting of inventor IDs in figure 3, whereas the calculated shares in figure 2 are based on fractional counting of patent applications. Although a region hosts three inventors of a patent, each of them holds one third of the patent. Accordingly, results from fractional and full counting are only identical when comparing the share of regions with $\mathrm{n}>0$ patent application with the share of regions with $\mathrm{n}>0$ inventor IDs. 
computations; viz. location quotients (LQ) and GINI coefficients. According to equation 4, figure 4 depicts the share of regions (\%) by technology field with a location quotient $L Q>1$. The figure clearly shows that the share of regions with $L Q>1$ within the sample of 819 micro regions has increased since the year 1977.

$<$ Figure 4 about here $>$

Our LQ analysis admittedly unveils that the share of regions with a location quotient $L Q>1$ in technology field $i$ is much smaller compared to the share of regions that have at least a single EPO patent application in technology field $i(n>0)$. Hence, we can show that the share of regions with a relative strong specialization is much smaller, as presented in figure 1 and 2, due to an explicit comparison of technology field specific patenting and overall EPO patenting. Here, figure 5 clearly illustrates that the number (and share) of regions with $L Q>1$ compared to the number (and share) of regions with $n>0$ EPO patent applications within the sample has decreased significantly within the last two decades (1988-90 vs. 20022004). ${ }^{32}$ This means that (i) the relative share of regions with strong specialization $(L Q>1)$ has decreased in Europe, (ii) that a relative larger share of European regions is involved in EPO patenting today, and (iii) that especially high-tech EPO patent applications experienced strong dispersion.

\section{$<$ Figure 5 about here $>$}

Besides fractional counting of patent applications and calculations of regional shares, we utilize GINI coefficients as a much more sophisticated inequality measure that satisfies several axioms. Therefore, this section provides the results from our computation of spatial and locational GINI coefficients $\left(G_{S P A C E}, G_{L O C}\right)$. In this respect, we are able to explore geographic concentration (inequality) of all technology fields by means of weighted GINI coefficients. Figures 6 and 7 summarize the observed inequality of European inventorship by means of population weighted $\left(y_{j}\right)$ and area surface weighted $\left(z_{j}\right)$ GINI coefficients for the periods 1988-2004 (population weighted GINI) and 1977-2004 (area surface weighted GINI). ${ }^{33}$

$<$ Figure 6 about here $>$

The technology fields TF12: paints \& varnishes, TF2: tobacco products, TF41: watches \& clocks, HT4: laser, TF16: man-made fibres, TF4: wearing apparel, TF5: leather articles and TF26: weapons \& ammunition show strong inequality coefficients and thus strong spatial concentration within the sample of 819 micro regions. In opposition, TF13: pharmaceuticals

$32 \quad$ We have calculated the yearly values for all technology fields since 1977.

33 Unfortunately, we are not able to calculate $G_{L O C}^{*}$ for the full reference period from 1977 onwards due to population data constraints. 
and TF10: basic chemical are determined by lower $G_{L O C}^{*}$ values; accordingly, the fields show much stronger dispersion across the regional sample. ${ }^{34}$.

Another important result of our $G_{L O C}^{*}$ computation, as illustrated in figure 6 , is that most technology fields are determined by strong dispersion tendencies of inventorship activity; these tendencies are also identified by focusing on the two aggregates "sum44tf" ( $\sum 44$ $\mathrm{TF}$ ) and "sumhightech" ( $\sum 6$ high-technology fields). We conclude that our calculated $G_{L O C}^{*}$ coefficients show that the distribution of EPO patent applications by technology field converges in the course of time to the distribution of area population for all 819 European micro regions. However, it should be noted that overall inequality persists at a very high level; thus, there are still many technology fields that are restricted to a handful of regions (figure 1; figure 6). As a consequence, a large fraction of European regions shows no inventorship activity at all. Finally, with respect to figure 6 , the technology field aggregates $\sum 44 \mathrm{TF}$ and $\sum 6$ high-technology fields show that (i) EPO patent applications are in general increasingly dispersing and that (ii) the aggregate of all six high technology fields shows similar dispersion tendencies across the sample of European micro regions (exceptions are HT4: laser and HT1: aviation).

Similar tendencies can be reported for the areal surface weighted GINI coefficients. The computed $G_{S P A C E}^{*}$ coefficients are illustrated in figure 7. Although the levels and dynamics (\%change) of $G_{S P A C E}^{*}$ differ to some extent from the population weighted alternative $\left(G_{L O C}^{*}\right)$, the coefficients still support the structures and tendencies described above. Moreover, we conclude that higher levels of $G_{S P A C E}^{*}$ compared to $G_{L O C}^{*}$ imply that population characteristics essentially differ from areal surface characteristics.

$<$ Figure 7 about here $>$

Besides the technology-specific levels of inequality in EPO patent applications, we are especially interested in the concentration dynamics. Figures 8 and 9 summarize technologyspecific inequality dynamics in terms of GINI coefficients (\%change) in the course of time; most of these results again support our Herfindahl-Hirschman measures for EPO patent applications and inventors (table 4 and 5).

Figure 8 highlights the dynamics of all 51 technology field aggregates under analysis; we take the arithmetic mean values of the yearly GINI coefficients for analyzing two periods: 1988-1990 and 2002-2004. It is clearly visible that the strongest process of de-concentration (\%change) and thus dispersion of inventorship activity across the sample of 819 regions concerns the following technology fields: TF10: basic chemicals, HT3: computer \& office machines, TF20: fabricated metal products, TF13: pharmaceuticals, TF33: other electrical equipment, TF43: other transport equipment, TF34: electronic components, TF31: accumulators \& battery, TF4: wearing, apparel, HT2: communication, TF35: signal transmission

34 TF28 and HT3 are very similar with respect to IPC codes; thus the GINI coefficients and inequality dynamics are almost identical 
\& telecommunications and TF18: non-metallic mineral products. The figure 8 contains technology-specific $G_{L O C}^{*}$ values, sorted by their rate of change.

$<$ Figure 8 about here $>$

Our $G_{S P A C E}^{*}$ computation shows the same dynamics of dispersion (\%change) when comparing 1988-1990 and 2002-2004, although inequality levels and thus the ranking of technology fields in terms of inequality coefficients differ from our $G_{L O C}^{*}$ measure; our $G_{S P A C E}^{*}$ results show (i) higher inequality and thus concentration in space and (ii) lower dynamics (\%change) due to a differing reference distribution (areal surface $z_{j}$ ). The results are visualized in figure 9 .

$<$ Figure 9 about here $>$

The \%change in inequality for the technology fields under analysis, from 1988-1990 to 2002-2004, is highest for the following technology fields: TF18: non-metallic mineral products, TF35: signal transmission \& telecommunications, TF10: basic chemical, TF33: other electrical equipment, HT2: communication, HT3: computer \& office machines, HT5: microorganisms \& genetics, TF19: basis metals, TF28: office machinery \& computer. Quite the contrary, TF26: weapons \& ammunition, TF41: watches \& clocks, TF2: tobacco products, HT4: laser, TF12: paints \& varnishes and TF14: soaps, detergents, toilet preparations have not dispersed across the 819 European micro regions. Several $G_{L O C}^{*}$ values have declined much more than their respective $G_{S P A C E}^{*}$ values. This can be explained by the fact that population characteristics have shifted in a different way compared to areal surface characteristics. Areal surface is assumed to be constant for the whole reference period. If population, in general, migrates from rural (peripheral) areas to capital regions, whereas EPO patenting generally shows increasing dispersion, we have to conclude that population weighted GINI coefficients decrease much stronger opposed to their spatial counterparts, because areal surface remains constant.

In the end, we are able to draw several conclusions: (i) technology-field specific inventorship activities highly differ in their distribution across the sample of 819 European micro regions; (ii) EPO patent applications and EPO inventors are similarly concentrated across the regional sample; (iii) the majority of regions only accounts for a few EPO patent applications and very small shares of EPO inventors; (iv) the majority of high-technology fields show by and large high levels of inequality; (v) several high-technology fields show strong dispersion tendencies for the periods 1988-1990 and 2002-2004; (vi) $G_{L O C}^{*}$ partially shows stronger changes than our $G_{S P A C E}^{*}$ alternative, although dispersion in terms of $G_{S P A C E}^{*}$ has been extraordinary high in the 1980s; (vii) both weighted GINI alternatives clearly reveal a decline in spatial concentration for almost all 52 technology field aggregates under analysis. 


\section{Summary and Conclusion}

This paper contributes with empirical findings to the research frontier on structural dynamics of European inventorship activity in several ways. Our analysis has to be recognized as a purely quantitative approach in the inequality and geographic concentration analysis tradition. We analyze the location, distribution and inequality of European inventorship activity in a spatial and technological context based on data extractions from our own relational database that makes use of OECD RegPAT (January 2009). The sample covers 819 European OECD TL3 micro regions (EU25+CH+NO) that add up to 904.917,129 EPO patent applications (fractional counting by priority date) and 1.616.257 inventor IDs (full counting by priority date) within the reference period 1977-2004. From a technology field point of view, aggregation and matching of the International Patent Classification (IPC) and 43 technology fields are accomplished by application of the ISI-SPRU-OST-concordance. In addition, we analyze the spatial characteristics of 6 selected high technology fields and 2 broad technology field aggregates.

The inequality and geographic concentration measures are accomplished by calculating standard descriptives, e.g. patent intensities (patent per million population), patent densities (patents per square kilometer), kurtosis, skewness and percentiles of the distributions. In addition, we compute traditional location quotients (LQ) and Herfindahl-Hirschman indices (HHI) with the latter being an alternative measure of spatial concentration. Moreover, the study makes use of technology field specific locational and spatial GINI coefficients. Population densities and areal surface characteristics differ tremendously across European regions, what supports our approach of controlling for geography. In this respect, GINI computations at the spatial level have to consider explicitly weights for the treatment of spatial heterogeneity of observations. Furthermore, we reveal that the distribution of EPO inventors (full counting) represents an acceptable proxy variable for EPO patent applications (fractional counting) across all technology fields.

Finally, we are able to draw several conclusions from our quantitative analysis with respect to the analyzed technology fields and their spatial characteristics: (i) the observed 51 technology fields (including 2 broad aggregates) highly differ in their distribution and thus geographic concentration across the sample of 819 European micro regions; (ii) technologyspecific EPO patent applications and EPO inventors are by and large similarly concentrated across the regional sample, although geographic dispersion has increased for most technology fields since the 1980s; (iii) the share of regions with $L Q>1$ has decreased compared to the share of regions with at least a single patent application what finally means dispersion; (iv) the majority of regions only account for small fractions of EPO patent applications and EPO inventors, which means that inventors are also highly concentrated in space; (v) a major fraction of high-technology fields shows high levels of inequality and thus geographic concentration; (vi) several high-technology fields show strong dispersion tendencies between 
1988-1990 and 2002-2004; (vii) locational GINI coefficients partially show stronger changes than their spatial GINI alternatives; (viii) inequality in terms of the spatial GINI has been extraordinary high in the 1980s; (ix) both weighted GINI alternatives clearly reveal a significant decline in spatial concentration for almost all 51 technology fields under analysis.

\section{References}

Acs, Z. J. (2002): Innovation and the Growth of Cities. Edward Elgar, Cheltenham.

ACs, Z. J., L. Anselin, And A. Varga (2002): "Patents and innovation counts as measures of regional production of new knowledge," Research Policy, 31(7), 1069-1085.

Aiginger, K., And M. Pfaffermayr (2004): "The Single Market and Geographic Concentration in Europe," Review of International Economics, 12(1), 1-11.

Amiti, M. (1999): "Specialization patterns in Europe," Review of World Economics (Weltwirtschaftliches Archiv), 135(4), 573-593.

Anselin, L. (2007): "Spatial econometrics in RSUE: Retrospect and prospect," Regional Science and Urban Economics, 37(4), 450-456.

ArBiA, G. (2001): "The role of spatial effects in empirical analysis of regional concentration," Journal of Geographical Systems, 3(3), 271-281.

Audretsch, D. B., And M. P. Feldman (1996): "R\&D Spillovers and the Geography of Innovation and Production," American Economic Review, 86(3), 630-40.

Audretsch, D. B., And M. P. Feldman (1999): "Innovation in cities: Science-based diversity, specialization and localized competition," European Economic Review, 43(2), $409-429$.

Baldwin, R. E., And P. Martin (2004): "Agglomeration and regional growth," in Handbook of Regional and Urban Economics, ed. by J. V. Henderson, and J. F. Thisse, vol. 4, chap. 60, pp. 2671-2713. Elsevier.

Bottazzi, L., And G. Peri (2003): "Innovation and spillovers in regions: Evidence from European patent data," European Economic Review, 47(4), 687-710.

Brakman, S., H. Garretsen, and C. van Marrewijk (2009): "Economic Geography Within And Between European Nations: The Role Of Market Potential And Density Across Space And Time," Journal of Regional Science, 49(4), 777-800.

Brakman, S., AND C. VAN MARREWiJK (2008): "It's a big world after all: on the economic impact of location and distance," Cambridge Journal of Regions, Economy and Society, $1(3), 411-437$. 
Breschi, S., And F. Lissoni (2009): "Mobility of skilled workers and co-invention networks: an anatomy of localized knowledge flows," Journal of Economic Geography, 9(4), 439-468.

BrülHART, M. (2001): "Evolving geographical concentration of European manufacturing industries," Review of World Economics (Weltwirtschaftliches Archiv), 137(2), 215-243.

Brulhart, M., and R. Traeger (2005): "An account of geographic concentration patterns in Europe," Regional Science and Urban Economics, 35(6), 597-624.

Christ, J. P. (2009): "The Geography and Co-location of European Technology-specific Coinventorship Networks," Violette Reihe Arbeitspapiere 31-2010, Promotionsschwerpunkt Globalisierung und Beschaeftigung.

Combes, P.-P., And H. G. Overman (2004): "The spatial distribution of economic activities in the European Union," in Handbook of Regional and Urban Economics, ed. by J. V. Henderson, and J. F. Thisse, vol. 4, chap. 64, pp. 2845-2909. Elsevier.

Crescenzi, R., A. Rodriguez-Pose, and M. Storper (2007): "The territorial dynamics of innovation: a Europe-United States comparative analysis," Journal of Economic Geography, 7, 673-709.

Duro, J. A. (2004): "Regional Income Inequalities in Europe: An Updated Measurement and Some Decomposition Results," Working Papers wpdea0411, Department of Applied Economics at Universitat Autonoma of Barcelona.

Ellison, G., And E. L. Glaeser (1997): "Geographic Concentration in U.S. Manufacturing Industries: A Dartboard Approach," Journal of Political Economy, 105(5), 889-927.

Feldman, M. P. (1994): The Geography of Innovation. Springer, Berlin.

Fornahl, D., And T. Brenner (2009): "Geographic concentration of innovative activities in Germany," Structural Change and Economic Dynamics, 20(3), 163-182.

Fotheringham, A., C. Brunsdon, and M. Charlton (2002): Geographically Weighted Regression: the analysis of spatially varying relationships. John Wiley Sons.

Frenken, K., And J. Hoekman (2006): "Convergence In An Enlarged Europe: The Role Of Network Cities," Tijdschrift voor Economische en Sociale Geografie, 97(3), 321-326.

Fujita, M., And P. Krugman (2003): "The new economic geography: Past, present and the future," Economics of Governance, 83(1), 139-164.

Fujita, M., P. Krugman, and A. J. Venables (2001): The Spatial Economy: Cities, Regions, and International Trade, vol. 1 of MIT Press Books. The MIT Press. 
Fujita, M., And T. Mori (2005): "Frontiers of the New Economic Geography," Working Papers 604, Kyoto University, Institute of Economic Research.

Gallagher, R. (2008): The Economics of Industrial Location: Agglomeration, CoAgglomeration, and Inventory Management. VDM Verlag Dr. Müller.

Greunz, L. (2005): "Intra- and Inter-regional Knowledge Spillovers: Evidence from European Regions," European Planning Studies, 13(3), 449-473.

Griliches, Z. (1979): "Issues in Assessing the Contribution of Research and Development to Productivity Growth," Bell Journal of Economics, 10(1), 92-116.

(1990): "Patent Statistics as Economic Indicators: A Survey," Journal of Economic Literature, 28(4), 1661-1707.

(1991): "Patent Statistics as Economic Indicators: A Survey," NBER Working Papers 3301, National Bureau of Economic Research, Inc.

Hinloopen, J., And C. van MarrewiJk (2004): "Locating Economic Concentration," Tinbergen Institute Discussion Papers 04-066/2, Tinbergen Institute.

Hoekman, J., K. Frenken, and F. van Oort (2008): "The geography of collaborative knowledge production in Europe," CESPRI Working Papers 214, CESPRI, Centre for Research on Innovation and Internationalisation, Universita' Bocconi, Milano, Italy.

Hoover, E. M. (1936): "The Measurement of Industrial Localization," The Review of Economics and Statistics, 18(4), 162-171.

JAFfe, A. B. (1989): "Real Effects of Academic Research," American Economic Review, $79(5), 957-70$.

Jaffe, A. B., M. Trajtenberg, and R. Henderson (1993): "Geographic Localization of Knowledge Spillovers as Evidenced by Patent Citations," The Quarterly Journal of Economics, 108(3), 577-98.

Jenkins, S. P., And P. V. Kerm (2009): "The Measurement of Economic Inequality," in The Oxford Handbook of Economic Inequality, ed. by T. M. S. Wiemar Salverda, Brian Nolan. Oxford University Press, first edn.

KeIlbach, M. (2000): Spatial Knowledge Spillovers and the Dynamics of Agglomeration and Regional Growth, Contributions to Economics. Physica-Verlag, A Springer-Verlag Company.

KIM, S. (1995): "Expansion of Markets and the Geographic Distribution of Economic Activities: The Tends in U.S. Regional Manufacturing Structure, 1860-1987," The Quarterly Journal of Economics, 110(4), 881-908. 
Knarvik, K. H. M., And F. Steen (1999): "Self-Reinforcing Agglomerations? An Empirical Industry Study," Scandinavian Journal of Economics, 101(4), 515-32.

Kroll, H. (2009): "Spillovers and Proximity in Perspective A Network Approach to Improving the Operationalisation of Proximity," Working Papers Firms and Region Nr. R4/2009, Fraunhofer ISI, Karlsruhe.

Krugman, P. (1992): Geography and Trade, vol. 1 of MIT Press Books. The MIT Press.

Krugman, R. B. P. (2001): "Agglomeration, Integration and Tax Harmonization," HEI Working Papers HEIWP01-2001, Economics Section, The Graduate Institute of International Studies.

Litzenberger, T. (2007): Cluster und die New Economic Geography - Theoretische Konzepte, empirische Tests und Konsequenzen für Regionalpolitik in Deutschland. Peter Lang, Deutschland.

Maraut, S., H. Dernis, C. Webb, V. Spiezia, and D. Guellec (2008): "The OeCD REGPAT Database: A Presentation," OECD Science, Technology and Industry Working Papers 2008/2, OECD, Directorate for Science, Technology and Industry.

Midelfart-Knarvik, K. H., H. G. Overman, and A. Venables (2003): "Monetary union and the economic geography of Europe," Open Access publications from London School of Economics and Political Science http://eprints.lse.ac.uk/, London School of Economics and Political Science.

Miguelez, E., And R. Moreno (2010): "Research Networks and Inventors Mobility as Drivers of Innovation: Evidence from Europe," IREA Working Papers 201001, University of Barcelona, Research Institute of Applied Economics.

Moreno, R., R. Paci, and S. Usai (2005): "Spatial spillovers and innovation activity in European regions," Environment and Planning A, 37(10), 1793-1812.

PaAs, T., And F. Schlitte (2006): "Regional Income Inequality and Convergence Processes in the EU-25," ERSA conference papers ersa06p229, European Regional Science Association.

Ponds, R., F. V. OORT, And K. Frenken (2010): "Innovation, spillovers and university, industry collaboration: an extended knowledge production function approach," Journal of Economic Geography, 10(2), 231-255.

Roos, M. (2002): "How important is geography for agglomeration?," ERSA conference papers ersa02p517, European Regional Science Association. 
Rosenthal, S. S., and W. C. Strange (2003): "Geography, Industrial Organization, and Agglomeration," The Review of Economics and Statistics, 85(2), 377-393.

SCHERNGELL, T. (2007): Interregionale Wissensspillovers in der Europäischen High-Tech Industrie: Eine Empirische Analyse. DUV Deutscher Universitäts-Verlag.

Schmoch, U., F. Laville, P. Patel, and R. Frietsch (2003): "Linking Technology Areas to Industrial Sectors: Final Report to the European Commission, DG Linking Technology Areas to Industrial Sectors: Final Report to the European Commission, DG Research," Discussion paper, DG Research.

Thompson, P., and M. Fox-Kean (2005): "Patent Citations and the Geography of Knowledge Spillovers: A Reassessment," American Economic Review, 95(1), 450-460.

UsAi, S. (2008): "The Geography of Inventive Activities in OECD Regions," OECD Science, Technology and Industry Working Papers 2008/3, OECD Directorate for Science, Technology and Industry. 


\section{Appendix}

Table 1: SQL Database Structure - EPO Patent Applications (RegPAT, 2008, 2009)

\section{FILE 1: EP_APPLT_REG (EPO appli- FILE 2: EP_INVT_REG (EPO inventor- cant) ship)}

\author{
2.126.580 hits \\ Appln_id (PATSTAT application ident.) \\ Appln_nr (patent application nr.) \\ Reg_code (NUTS3 region code) \\ Address \\ Ctry_code (country code) \\ Reg_share (share $\leq 1)$ \\ Applt_share (applicant share $\leq 1$ )
}

\author{
4.897.220 hits \\ Appln_id (PATSTAT application ident.) \\ Appln_nr (patent application nr.) \\ Reg_code (NUTS3 region code) \\ Address \\ Ctry_code (country code) \\ Reg_share (share $\leq 1)$ \\ Invt_share (inventor share $\leq 1$ )
}

\section{FILE 3: EP_PRIO_IPC (YEAR, IPC)}

\section{FILE 4: RegPAT_REGIONS (Concor-} dance)
9.521.012 hits

Appln_nr (patent application nr.)

Appn_year (filing year)

Prio_year (priority year of first filing)

IPC (IPC classes 8th edition)
Ctry_code (Country)

Up_level_code (NUTS2 level code)

Up_level_label (macro level region's name)

Reg_code (NUTS3 level code)

Reg_label (micro level region's name)

\section{FILE 5: IPC Concordance}

628 IPC fields vs. 44 technology fields

628 IPC fields vs. 44 NACE fields

Source: own illustration. Notes: The relational database covers 819 OECD Territorial Levels TL3 micro regions. For Belgium, Greece and the Netherlands, the OECD TL3 corresponds to the EUROSTAT NUTS2

level. For Germany, we make use of 97 "Raumordnungsregionen". Inventor counting is based on full counting method. IDs are counted several times if inventor IDs correspond to several technology fields. 
Table 2: RegPAT data and the NUTS3/TL3 classification

\begin{tabular}{|c|c|c|c|c|c|}
\hline Ctry. & Label & $\begin{array}{l}\text { Micro- } \\
\text { Region } \\
\text { (NUTS3) }\end{array}$ & $\begin{array}{l}\text { Micro- } \\
\text { Region } \\
\text { (TL3) }\end{array}$ & $\begin{array}{l}\text { Meso- } \\
\text { Region } \\
\text { (NUTS2) }\end{array}$ & $\begin{array}{l}\text { Macro- } \\
\text { Region } \\
\text { (NUTS1) }\end{array}$ \\
\hline
\end{tabular}

\begin{tabular}{|c|c|c|c|c|c|c|}
\hline $\mathrm{AT}$ & Austria & 35 NUTS3 & 35 TL3 & 9 NUTS2 & 3 NUTS1 & 43.084 \\
\hline $\mathrm{BE}$ & Belgium & 43 NUTS3 & 11 TL3 & 11 NUTS2 & 3 NUTS1 & 48.362 \\
\hline $\mathrm{CH}$ & Switzerland & 26 NUTS3 & 26 TL3 & 7 NUTS2 & 7 NUTS1 & 105.939 \\
\hline $\mathrm{CY}$ & Cyprus & 1 NUTS3 & 1 TL3 & 1 NUTS2 & 1 NUTS1 & 168 \\
\hline $\mathrm{CZ}$ & Czech Republic & 14 NUTS3 & 14 TL3 & 8 NUTS2 & 8 NUTS1 & 2.956 \\
\hline $\mathrm{DE}$ & Germany & 439 NUTS3 & 97 TL3 & 41 NUTS2 & 16 NUTS1 & 940.797 \\
\hline DK & Denmark & 15 NUTS3 & 15 TL3 & 1 NUTS2 & 1 NUTS1 & 32.851 \\
\hline $\mathrm{EE}$ & Estonia & 5 NUTS3 & 5 TL3 & 1 NUTS2 & 1 NUTS1 & 323 \\
\hline $\mathrm{ES}$ & Spain & 52 NUTS3 & 52 TL3 & 19 NUTS2 & 7 NUTS1 & 25.689 \\
\hline FI & Finland & 20 NUTS3 & 20 TL3 & 5 NUTS2 & 4 NUTS1 & 47.212 \\
\hline $\mathrm{FR}$ & France & 100 NUTS3 & 100 TL3 & 26 NUTS2 & 9 NUTS1 & 302.475 \\
\hline GR & Greece & 51 NUTS3 & 13 TL3 & 13 NUTS2 & 4 NUTS1 & 2061 \\
\hline $\mathrm{HU}$ & Hungary & 20 NUTS3 & 20 TL3 & 7 NUTS2 & 3 NUTS1 & 12.719 \\
\hline IE & Ireland & 8 NUTS3 & 8 TL3 & 2 NUTS2 & 2 NUTS1 & 8.021 \\
\hline IT & Italy & 103 NUTS3 & 103 TL3 & 21 NUTS2 & 5 NUTS1 & 125.173 \\
\hline $\mathrm{LT}$ & Lithuania & 10 NUTS3 & 10 TL3 & 1 NUTS2 & 10 NUTS1 & 309 \\
\hline $\mathrm{LU}$ & Luxembourg & 1 NUTS3 & 1 TL3 & 1 NUTS2 & 1 NUTS1 & 2.923 \\
\hline $\mathrm{LV}$ & Latvia & 6 NUTS3 & 6 TL3 & 1 NUTS2 & 6 NUTS1 & 360 \\
\hline $\mathrm{MT}$ & Malta & 2 NUTS3 & 1 TL3 & 1 NUTS2 & 2 NUTS1 & 106 \\
\hline NL & Netherlands & 40 NUTS3 & 12 TL3 & 12 NUTS2 & 4 NUTS1 & 95.286 \\
\hline $\mathrm{NO}$ & Norway & 19 NUTS3 & 19 TL3 & 7 NUTS2 & 7 NUTS1 & 15.691 \\
\hline $\mathrm{PL}$ & Poland & 45 NUTS3 & 45 TL3 & 16 NUTS2 & 6 NUTS1 & 3.809 \\
\hline $\mathrm{PT}$ & Portugal & 30 NUTS3 & 30 TL3 & 7 NUTS2 & 3 NUTS1 & 1.433 \\
\hline $\mathrm{SE}$ & Sweden & 21 NUTS3 & 21 TL3 & 8 NUTS2 & 8 NUTS1 & 86.369 \\
\hline SI & Slovenia & 12 NUTS3 & 12 TL3 & 1 NUTS2 & 12 NUTS1 & 1.939 \\
\hline SK & Slovak Republic & 8 NUTS3 & 8 TL3 & 4 NUTS2 & 4 NUTS1 & 731 \\
\hline UK & United Kingdom & 133 NUTS3 & 133 TL3 & 37 NUTS2 & 12 NUTS1 & 237.390 \\
\hline$\sum$ & 27 NUTS0 & 1259 NUTS3 & 819 TL3 & 268 NUTS2 & 149 NUTS1 & 2.144 .176 \\
\hline
\end{tabular}

Source: own illustration. Notes: The relational database covers 819 OECD Territorial Levels TL3 micro regions. For Belgium, Greece and the Netherlands, the OECD TL3 corresponds to the EUROSTAT NUTS2 level. For Germany, we make use of 97 "Raumordnungsregionen". 
Table 3: IPC - Technology Field Concordance

\begin{tabular}{|c|c|c|}
\hline No. & Field Name (Technology) & IIPC Subclasses \\
\hline TF1 & Food, beverages & $\mathrm{A} 01 \mathrm{H}, \mathrm{A} 21 \mathrm{D}, \mathrm{A} 23 \mathrm{~B}, \mathrm{~A} 23 \mathrm{C}, \mathrm{A} 23 \mathrm{D}, \mathrm{A} 23 \mathrm{~F}, \mathrm{~A} 23 \mathrm{G}, \mathrm{A} 23 \mathrm{~J}, \mathrm{~A} 23 \mathrm{~K}, \mathrm{~A} 23 \mathrm{~L}, \mathrm{~A} 23 \mathrm{P}, \mathrm{C} 12 \mathrm{C}, \mathrm{C} 12 \mathrm{~F}, \mathrm{C} 12 \mathrm{G}, \mathrm{C} 12 \mathrm{H}, \mathrm{C} 12 \mathrm{~J}, \mathrm{C} 13 \mathrm{~F}, \mathrm{C} 13 \mathrm{~J}, \mathrm{C} 13 \mathrm{~K}$ \\
\hline TF2 & Tobacco products & A24B, A24D, A24F \\
\hline TF3 & Textiles & D04D, D04G, D04H, D06C, D06J, D06M, D06N, D06P, D06Q \\
\hline TF4 & Wearing apparel & A41B, A41C, A41D, A41F \\
\hline TF5 & Leather articles & A43B, A43C, B68B, B68C \\
\hline TF6 & Wood products & B27D, B27H, B27M, B27N, E04G \\
\hline TF7 & Paper & B41M, B42D, B42F, B44F, D21C, D21H, D21J \\
\hline TF9 & Petroleum products, nuclear fuel & C10G, C10L, G01V \\
\hline TF10 & Basic chemical & $\begin{array}{l}\text { B01J, B09B, B09C, B29B, C01B, C01C, C01D, C01F, C01G, C02F, C05B, C05C, C05D, C05F, C05G, C07B, C07C, C07F, C07G, C08B, C08C, C08F, C08G, C08J, C08K, C08L, C09B, C09C, C09D, } \\
\text { C09K, C10B, C10C, C10H, C10J, C10K, C12S, C25B, F17C, F17D, F25J, G21F }\end{array}$ \\
\hline TF11 & Pesticides \& agro-chemical prod. & A01N \\
\hline TF12 & Paints, varnishes & B27K \\
\hline TF13 & Pharmaceuticals & A61K, A61P, C07D, C07H, C07J, C07K, C12N, C12P, C12Q \\
\hline TF14 & Soaps \& detergents & C09F, C11D, D06L \\
\hline TF15 & Other chemicals & A62D, C06B, C06C, C06D, C08H, C09G, C09H, C09J, C10M, C11B, C11C, C14C, C23F, C23G, D01C, F42B, F42D, G03C \\
\hline TF16 & Man-made fibres & D01F \\
\hline TF17 & Rubber and plastics products & A45C, B29C, B29D, B60C, B65D, B67D, E02B, F16L, H02G \\
\hline TF18 & Non-metallic mineral products & B24D, B28B, B28C, B32B, C03B, C03C, C04B, E04B, E04C, E04D, E04F, G21B \\
\hline TF19 & Basic metals & B21C, B21G, B22D, C21B, C21C, C21D, C22B, C22C, C22F, C25C, C25F, C30B, D07B, E03F, E04H, F27D, H01B \\
\hline TF20 & Fabricated metal products & $\begin{array}{l}\text { A01L, A44B, A47H, A47K, B21K, B21L, B22F, B25B, B25C, B25F, B25G, B25H, B26B, B27G, B44C, B65F, B82B, C23D, C25D, E01D, E01F, E02C, E03B, E03C, E03D, E05B, E05C, E05D, E05F, } \\
\text { E05G, E06B, F01K, F15D, F16B, F16P, F16S, F16T, F17B, F22B, F22G, F24J, G21H }\end{array}$ \\
\hline TF21 & Energy machinery & B23F, F01B, F01C, F01D, F03B, F03C, F03D, F03G, F04B, F04C, F04D, F15B, F16C, F16D, F16F, F16H, F16K, F16M, F23R \\
\hline TF22 & Non-specific purpose machinery & $\begin{array}{l}\text { A62C, B01D, B04C, B05B, B61B, B65G, B66B, B66C, B66D, B66F, C10F, C12L, F16G, F22D, F23B, F23C, F23D, F23G, F23H, F23J, F23K, F23L, F23M, F24F, F24H, F25B, F27B, F28B, F28C, F28D, } \\
\text { F28F, F28G, G01G, H05F }\end{array}$ \\
\hline TF23 & Agricultural \& forestry mach. & A01B, A01C, A01D, A01F, A01G, A01J, A01K, A01M, B27L \\
\hline TF24 & Machine-tools & B21D, B21F, B21H, B21J, B23B, B23C, B23D, B23G, B23H, B23K, B23P, B23Q, B24B, B24C, B25D, B25J, B26F, B27B, B27C, B27F, B27J, B28D, B30B, E21C \\
\hline TF25 & Special purpose machinery & $\begin{array}{l}\text { A21C, A22B, A22C, A23N, A24C, A41H, A42C, A43D, B01F, B02B, B02C, B03B, B03C, B03D, B05C, B05D, B06B, B07B, B07C, B08B, B21B, B22C, B26D, B31B, B31C, B31D, B31F, B41B, B41C, } \\
\text { B41D, B41F, B41G, B41L, B41N, B42B, B42C, B44B, B65B, B65C, B65H, B67B, B67C, B68F, C13C, C13D, C13G, C13H, C14B, C23C, D01B, D01D, D01G, D01H, D02G, D02H, D02J, D03C, D03D, } \\
\text { D03J, D04B, D04C, D05B, D05C, D06B, D06G, D06H, D21B, D21D, D21F, D21G, E01C, E02D, E02F, E21B, E21D, E21F, F04F, F16N, F26B, H05H }\end{array}$ \\
\hline TF26 & Weapons and ammunition & B63G, F41A, F41B, F41C, F41F, F41G, F41H, F41J, F42C, G21J \\
\hline TF27 & Domestic appliances & A21B, A45D, A47G, A47J, A47L, B01B, D06F, E06C, F23N, F24B, F24C, F24D, F25C, F25D, H05B \\
\hline TF28 & Office machinery and computers & B41J, B41K, B43M, G02F, G03G, G05F, G06C, G06D, G06E, G06F, G06G, G06J, G06K, G06M, G06N, G06T, G07B, G07C, G07D, G07F, G07G, G09D, G09G, G10L, G11B, H03K, H03L \\
\hline TF29 & Electric motors, generators & $\mathrm{H} 02 \mathrm{~K}, \mathrm{H} 02 \mathrm{~N}, \mathrm{H} 02 \mathrm{P}$ \\
\hline TF30 & Electric distribution, control, wire, cable & $\mathrm{H} 01 \mathrm{H}, \mathrm{H} 01 \mathrm{R}, \mathrm{H} 02 \mathrm{~B}$ \\
\hline TF31 & Accumulators, battery & H01M \\
\hline TF32 & Lighting equipment & F21H, F21K, F21L, F21M, F21S, F21V, H01K \\
\hline TF33 & Other electrical equipment & B60M, B61L, F21P, F21Q, G08B, G08G, G10K, G21C, G21D, H01T, H02H, H02M, H05C \\
\hline TF34 & Electronic components & B81B, B81C, G11C, H01C, H01F, H01G, H01J, H01L \\
\hline TF35 & Signal transmission, telecomms & G09B, G09C, H01P, H01Q, H01S, H02J, H03B, H03C, H03D, H03F, H03G, H03H, H03M, H04B, H04J, H04K, H04L, H04M, H04Q, H05K \\
\hline TF36 & TV \& radio receivers, audiovisual electronics & G03H, H03J, H04H, H04N, H04R, H04S \\
\hline TF37 & Medical equipment & A61B, A61C, A61D, A61F, A61G, A61H, A61J, A61L, A61M, A61N, A62B, B01L, B04B, C12M, G01T, G21G, G21K, H05G \\
\hline TF38 & Measuring instruments & F15C, G01B, G01C, G01D, G01F, G01H, G01J, G01M, G01N, G01R, G01S, G01W, G12B \\
\hline TF39 & Industrial process control equip. & G01K, G01L, G05B, G08C \\
\hline TF40 & Optical instruments & G02B, G02C, G03B, G03D, G03F, G09F \\
\hline TF41 & Watches, clocks & G04B, G04C, G04D, G04F, G04G \\
\hline TF42 & Motor vehicles & B60B, B60D, B60G, B60H, B60J, B60K, B60L, B60N, B60P, B60Q, B60R, B60S, B60T, B62D, E01H, F01L, F01M, F01N, F01P, F02B, F02D, F02F, F02G, F02M, F02N, F02P, F16J, G01P, G05D, G05G \\
\hline TF43 & Other transport equipment & B60F, B60V, B61C, B61D, B61F, B61G, B61H, B61J, B61K, B62C, B62H, B62J, B62K, B62L, B62M, B63B, B63C, B63H, B63J, B64B, B64C, B64D, B64F, B64G, E01B, F02C, F02K, F03H \\
\hline TF44 & Furniture, consumer goods & $\begin{array}{l}\text { A41G, A42B, A44C, A45B, A45F, A46B, A46D, A47B, A47C, A47D, A47F, A63B, A63C, A63D, A63F, A63G, A63H, A63J, A63K, B43K, B43L, B44D, B62B, B68G, C06F, F23Q, G10B, G10C, G10D, } \\
\text { G10F, G10G, G10H }\end{array}$ \\
\hline HT1 & Aviation & B64B, B64C, B64D, B64F, B64G \\
\hline HT2 & Computers and automated business equipment & B41J, G06C, G06D, G06E, G06F, G06G, G06J, G06K, G06M, G06N, G06T, G11C \\
\hline HT3 & Lasers & Ho1s \\
\hline HT4 & Semiconductors & H01L \\
\hline HT5 & Communication technology & H04B, H04H, H04J, H04K, H04L, H04M, H04N, H04Q, H04R, H04S \\
\hline HT6 & Micro-organism and genetic engineering & C12M, C12N, C12P, C12Q \\
\hline
\end{tabular}

Source: own illustration. 
Table 4: Descriptives: EPO Patent Applications (fractional counting of applications) by Technology Field

\begin{tabular}{|c|c|c|c|c|c|c|c|c|c|c|c|c|c|c|c|c|c|c|c|c|c|c|c|c|c|c|c|}
\hline \multirow[b]{2}{*}{ TF Label } & \multicolumn{11}{|c|}{ 1990-1992 (mean value) } & \multicolumn{11}{|c|}{ 2002-2004 (mean value) } & \multicolumn{5}{|c|}{ \%change } \\
\hline & $\begin{array}{c}\text { (1a) } \min \\
\mathrm{nb}\end{array}$ & $\begin{array}{c}\text { (2a) } \max \\
n b\end{array}$ & $\begin{array}{l}\text { (3a) max } \\
\text { reg share }\end{array}$ & $\begin{array}{c}(4 a) \\
\text { mean nb }\end{array}$ & $\begin{array}{l}\text { (5a) } \\
\text { P30 }\end{array}$ & $\begin{array}{l}\text { (6a) } \\
\text { P70 }\end{array}$ & $\begin{array}{c}\text { (7a) total } \\
\text { nb }\end{array}$ & $\begin{array}{c}\text { (8a) kurt } \\
\text { nb }\end{array}$ & $\begin{array}{l}\text { (9a) skew } \\
\text { nb }\end{array}$ & $\begin{array}{c}(10 \mathrm{a}) \\
\mathrm{HHI} \\
\end{array}$ & $\begin{array}{c}\text { (11a) } \\
\text { regions } \mathrm{n}>0 \\
\text { patents }\end{array}$ & $\begin{array}{c}(1 b) \min \\
\mathrm{nb}\end{array}$ & $\begin{array}{c}(2 b) \max \\
n b\end{array}$ & $\begin{array}{l}\text { (3b) max } \\
\text { reg share }\end{array}$ & $\begin{array}{c}(4 b) \\
\text { mean nb }\end{array}$ & $\begin{array}{l}(5 b) \\
\text { P30 }\end{array}$ & $\begin{array}{l}\text { (6b) } \\
\text { P70 }\end{array}$ & $\begin{array}{c}\text { (7b) total } \\
\text { nb }\end{array}$ & $\begin{array}{c}(8 b) \text { kurt } \\
\text { nb }\end{array}$ & $\begin{array}{c}(9 \mathrm{~b}) \\
\text { skew nb }\end{array}$ & $\begin{array}{l}(10 \mathrm{~b}) \\
\mathrm{HHI}\end{array}$ & $\begin{array}{c}(11 \mathrm{~b}) \text { regions } \\
\mathrm{n}>0 \text { patents }\end{array}$ & $\begin{array}{c}\Delta(\mathrm{P} 70-\mathrm{P} 30) \\
(6)-(5)\end{array}$ & $\begin{array}{c}\Delta \text { kurt } \\
(8)\end{array}$ & $\begin{array}{c}\Delta \text { skew } \\
(9)\end{array}$ & $\begin{array}{c}\Delta \mathrm{HHI} \\
(10)\end{array}$ & $\begin{array}{c}\Delta \text { regions } \\
n>0 \text { patents } \\
\text { (11) }\end{array}$ \\
\hline SUM_44_TF & 0,0 & 928,0 & $3,1 \%$ & 37,0 & 1,8 & 23,9 & 30319,64 & 40,8 & 5,6 & 0,008 & 648 & 0,0 & 2004,7 & $3,6 \%$ & 67,1 & 5,2 & 43,2 & 54977,8 & 61,4 & 6,5 & 0,008 & 748 & $72,0 \%$ & $50,4 \%$ & $15,5 \%$ & $0,0 \%$ & $15,5 \%$ \\
\hline TF1_Food_beverages & 0,0 & 29,7 & $6,1 \%$ & 0,6 & 50,0 & 0,3 & 491,19 & 118,5 & 8,6 & 0,011 & 237 & 0,0 & 35,7 & $4,5 \%$ & 1,0 & 0,0 & 0,6 & 794,6 & 56,4 & 6,2 & 0,010 & 318 & $71,6 \%$ & $-52,4 \%$ & $-27,7 \%$ & $-10,9 \%$ & $34,3 \%$ \\
\hline TF2_Tobacco_prod & 0,0 & 3,4 & $4 \quad 11,5 \%$ & 0,0 & 0,0 & 0,0 & 29,59 & 173,7 & 10,8 & 0,031 & 30 & 0,0 & 11,8 & $20,1 \%$ & 0,1 & 0,0 & 0,0 & 58,4 & 328,8 & 17,4 & 0,088 & 39 & & $89,3 \%$ & $61,1 \%$ & $188,7 \%$ & $30,0 \%$ \\
\hline TF3_Textiles & 0,0 & 25,6 & $\begin{array}{ll}6 \quad 7,4 \% \\
\end{array}$ & 0,4 & $\begin{array}{l}0,0 \\
+4\end{array}$ & 0,1 & 347,17 & 102,2 & 9,3 & 0,023 & 163 & 0,0 & 13,9 & $4,3 \%$ & 0,4 & 0,0 & 0,2 & 322,1 & 46,3 & 6,0 & 0,012 & 184 & $100,0 \%$ & $-54,7 \%$ & $-35,7 \%$ & $-46,7 \%$ & $13,1 \%$ \\
\hline TF4_Wearing_apparel & 0,0 & 2,2 & $5,6 \%$ & 0,0 & 0,0 & 0,0 & 38,55 & 62,8 & 6,8 & 0,018 & 37 & 0,0 & 4,3 & $3,6 \%$ & 0,1 & 0,0 & 0,0 & 121,5 & 32,9 & 5,1 & 0,011 & 95 & - & $-47,6 \%$ & $-24,9 \%$ & $-38,2 \%$ & $159,1 \%$ \\
\hline TF5_Leather_articles & 0,0 & 19,4 & $4 \quad 23,4 \%$ & 0,1 & 0,0 & 0,0 & 83,00 & 455,0 & 20,0 & 0,076 & 50 & 0,0 & 22,0 & $16,5 \%$ & 0,2 & 0,0 & 0,0 & 133,1 & 439,8 & 18,9 & 0,038 & 89 & 9 & $-3,3 \%$ & $-5,4 \%$ & $-49,8 \%$ & $79,9 \%$ \\
\hline TF6_Wood_prod & 0,0 & 6,4 & $4,6 \%$ & 0,2 & 0,0 & 0,0 & 140,03 & 54,0 & 5,9 & 0,011 & 104 & 0,0 & 7,0 & $3,8 \%$ & 0,2 & 0,0 & 0,2 & 184,0 & 43,7 & 5,4 & 0,008 & 136 & & $-19,2 \%$ & $-9,9 \%$ & $-19,7 \%$ & $31,5 \%$ \\
\hline TF7_Paper & 0,0 & 20,3 & $4,9 \%$ & 0,5 & 0,0 & 0,3 & 413,77 & 59,0 & 6,7 & 0,013 & 201 & 0,0 & 22,2 & $4,0 \%$ & 0,7 & 0,0 & 0,3 & 554,9 & 40,6 & 5,4 & 0,010 & 231 & $0,0 \%$ & $-31,2 \%$ & $-18,6 \%$ & $-19,7 \%$ & $15,3 \%$ \\
\hline TF9_Petrol_prod_nucl_fuel & 0,0 & 15,3 & $7,0 \%$ & 0,3 & 0,0 & 0,0 & 219,81 & 98,7 & 8,8 & 0,020 & 132 & 0,0 & 15,4 & $5,0 \%$ & 0,4 & 0,0 & 0,1 & 305,7 & 61,1 & 6,8 & 0,014 & 177 & , & $-38,1 \%$ & $-22,6 \%$ & $-30,5 \%$ & $34,7 \%$ \\
\hline TF10_Basic_chemical & 0,0 & 267,5 & $5,8 \%$ & 5,6 & 0,1 & 2,5 & 4592,35 & 105,6 & 9,4 & 0,017 & 473 & 0,0 & 197,2 & $4,3 \%$ & 5,6 & 0,3 & 3,1 & 4618,4 & 65,6 & 7,1 & 0,011 & 552 & $16,9 \%$ & $-37,9 \%$ & $-24,1 \%$ & $-36,1 \%$ & $16,8 \%$ \\
\hline TF11_Pesticide_agrochem_prod & 0,0 & 46,1 & $111,6 \%$ & 0,5 & 0,0 & 0,1 & 396,69 & 153,7 & 11,7 & 0,046 & 162 & 0,0 & 52,4 & $\begin{array}{l}4 \quad 13,2 \% \\
\end{array}$ & 0,5 & 0,0 & 0,1 & 397,1 & 178,3 & 12,2 & 0,043 & 167 & $66,7 \%$ & $16,0 \%$ & $3,7 \%$ & $-7,1 \%$ & $3,3 \%$ \\
\hline TF12_Paints_varnishes & 0,0 & 6,2 & \begin{tabular}{|l|l}
$20,5 \%$ \\
\end{tabular} & 0,0 & 0,0 & 0,0 & 30,37 & 397,1 & 17,7 & 0,061 & 29 & 0,0 & 1,3 & $6,1 \%$ & 0,0 & 0,0 & 0,0 & 22,0 & 57,4 & 6,8 & 0,026 & 27 & & $-85,5 \%$ & $-61,5 \%$ & $-57,3 \%$ & $-5,8 \%$ \\
\hline TF13_Pharmaceuticals & 0,0 & 128,9 & $4,1 \%$ & 3,8 & 0,0 & 1,3 & 3137,18 & 45,4 & 6,0 & 0,013 & 408 & 0,0 & 166,4 & $2,8 \%$ & 7,3 & 0,2 & 3,0 & 5961,6 & 24,5 & 4,5 & 0,010 & 551 & $118,1 \%$ & $-46,2 \%$ & $-24,7 \%$ & $-24,6 \%$ & $35,0 \%$ \\
\hline TF14_Soaps_detergents & 0,0 & 65,9 & \begin{tabular}{l|}
$9 \quad 19,8 \%$ \\
\end{tabular} & 0,4 & $+0,0$ & 0,0 & 332,17 & 408,0 & 18,3 & 0,057 & 131 & 0,0 & 42,3 & $12,5 \%$ & 0,4 & 0,0 & 0,0 & 337,8 & 196,8 & 12,6 & 0,036 & 148 & & $-51,8 \%$ & $-31,3 \%$ & $-36,4 \%$ & $13,2 \%$ \\
\hline TF15_Other_chemicals & 0,0 & 41,1 & $1 \quad 5,7 \%$ & 0,9 & 0,0 & 0,3 & 723,04 & 89,7 & 8,3 & 0,015 & 253 & 0,0 & 32,8 & $\begin{array}{l}5,5 \% \\
\end{array}$ & 0,7 & 0,0 & 0,3 & 593,6 & 81,8 & 7,7 & 0,013 & 249 & $0,0 \%$ & $-8,8 \%$ & $-8,3 \%$ & $-17,4 \%$ & $-1,4 \%$ \\
\hline TF16_Man_made_fibre & 0,0 & 6,3 & $8,8 \%$ & 0,1 & 0,0 & 0,0 & 71,25 & 101,5 & 9,0 & 0,032 & 55 & 0,0 & 5,3 & $7,8 \%$ & 0,1 & 0,0 & 0,0 & 68,6 & 94,3 & 8,1 & 0,020 & 71 & & $-7,1 \%$ & $-10,1 \%$ & $-36,7 \%$ & $28,9 \%$ \\
\hline TF17_Rubber_plastic_prod & 0,0 & 52,8 & $2,3 \%$ & 2,8 & 0,0 & 2,2 & 2326,07 & 20,2 & 4,0 & 0,006 & 429 & 0,0 & 66,5 & $2,1 \%$ & 3,9 & 0,3 & 3,2 & 3234,5 & 22,2 & 4,0 & 0,006 & 520 & $33,6 \%$ & $10,0 \%$ & $1,5 \%$ & $-11,0 \%$ & $21,2 \%$ \\
\hline TF18_Non-metal_mineral_prod & 0,0 & 51,2 & $3,6 \%$ & 1,7 & 0,0 & 1,3 & 1417,57 & 43,3 & 5,3 & 0,007 & 375 & 0,0 & 45,5 & $2,4 \%$ & 2,3 & 0,1 & 1,7 & 1869,4 & 22,9 & 4,0 & 0,006 & 450 & $23,9 \%$ & $-47,1 \%$ & $-24,8 \%$ & $-23,5 \%$ & $20,2 \%$ \\
\hline TF19_Basic_metals & 0,0 & 36,9 & $3,9 \%$ & 1,1 & 0,0 & 0,8 & 937,91 & 59,2 & 6,4 & 0,009 & 321 & 0,0 & 41,1 & $3,8 \%$ & 1,3 & 0,0 & 1,0 & 1071,0 & 55,9 & 6,2 & 0,008 & 369 & $28,6 \%$ & $-5,6 \%$ & $-3,8 \%$ & $-12,5 \%$ & $14,8 \%$ \\
\hline TF20_Fabric_metal_prod & 0,0 & 73,9 & $4,3 \%$ & 2,1 & 0,0 & 1,7 & 1732,98 & 75,8 & 7,1 & 0,009 & 390 & 0,0 & 119,3 & $4,4 \%$ & 3,3 & 0,2 & 2,5 & 2740,4 & 80,9 & 7,3 & 0,008 & 483 & $40,8 \%$ & $6,7 \%$ & $2,5 \%$ & $-6,5 \%$ & $24,0 \%$ \\
\hline TF21_Energy_machinery & 0,0 & 82,4 & $5,1 \%$ & 2,0 & 0,0 & 1,2 & 1610,90 & 80,3 & 7,2 & 0,010 & 343 & 0,0 & 173,6 & $5,7 \%$ & 3,7 & 0,1 & 2,1 & 3071,1 & 98,5 & 8,1 & 0,011 & 451 & $61,7 \%$ & $22,7 \%$ & $12,1 \%$ & $8,3 \%$ & $31,7 \%$ \\
\hline TF22_Nonspec_machinery & 0,0 & 72,9 & $3,2 \%$ & 2,8 & 0,0 & 1,9 & 2289,36 & 37,5 & 5,2 & 0,008 & 434 & 0,0 & 219,7 & $7,2 \%$ & 3,7 & 0,3 & 2,6 & 3054,1 & 266,0 & 13,2 & 0,010 & 502 & $21,4 \%$ & $609,4 \%$ & $154,8 \%$ & $33,2 \%$ & $15,7 \%$ \\
\hline TF23_Agricul_forestry_machinery & 0,0 & 24,1 & $4,4 \%$ & 0,7 & 0,0 & 0,4 & 543,86 & 69,6 & 7,0 & 0,009 & 244 & 0,0 & 35,7 & $4,4 \%$ & 1,0 & 0,0 & 0,8 & 805,5 & 82,3 & 7,8 & 0,009 & 313 & $68,8 \%$ & $18,2 \%$ & $11,2 \%$ & $0,3 \%$ & $28,0 \%$ \\
\hline TF24_Machine_tools & 0,0 & 89,8 & & 1,6 & \begin{tabular}{|l|l}
5 & 0,0 \\
$r$
\end{tabular} & 0,9 & 1296,50 & 184,0 & 10,8 & 0,011 & 338 & 0,0 & 131,9 & $7,3 \%$ & 2,2 & 0,0 & 1,3 & 1800,3 & 206,2 & 11,6 & 0,012 & 390 & $41,2 \%$ & $12,1 \%$ & $7,4 \%$ & $5,2 \%$ & $15,5 \%$ \\
\hline TF25_Spec_purp_machinery & 0,0 & 145,5 & $4,0 \%$ & 4,4 & 0,0 & 2,9 & 3602,14 & 57,1 & 6,2 & 0,008 & 466 & 0,0 & 122,8 & $2,7 \%$ & 5,5 & 0,3 & 3,7 & 4493,7 & 31,9 & 4,9 & 0,007 & 532 & $15,0 \%$ & $-44,2 \%$ & $-22,1 \%$ & $-13,3 \%$ & $14,2 \%$ \\
\hline TF26_Weapons_ammunition & 0,0 & 8,7 & $6,0 \%$ & 0,2 & 0,0 & 0,0 & 144,98 & 70,2 & 7,2 & 0,017 & 94 & 0,0 & 13,1 & $6,5 \%$ & 0,2 & 0,0 & 0,0 & 200,2 & 78,2 & 7,8 & 0,019 & 114 & & $11,3 \%$ & $8,5 \%$ & $9,2 \%$ & $21,2 \%$ \\
\hline TF27_Domestic_appliances & 0,0 & 35,5 & $3,6 \%$ & 1,2 & 0,0 & 0,8 & 981,18 & 38,8 & 5,3 & 0,009 & 300 & 0,0 & 66,6 & $3,5 \%$ & 2,3 & 0,0 & 1,6 & 1917,9 & 41,6 & 5,7 & 0,009 & 415 & $106,3 \%$ & $7,3 \%$ & $6,3 \%$ & $-0,5 \%$ & $38,3 \%$ \\
\hline TF28_Office_mach_computers & 0,0 & 149,5 & $7,6 \%$ & 2,4 & $\begin{array}{l}0,0 \\
+\end{array}$ & 0,9 & 1956,99 & 129,1 & 10,1 & 0,020 & 327 & 0,0 & 556,6 & $6 \quad 11,9 \%$ & 5,7 & 0,1 & 2,3 & 4684,7 & 325,6 & 15,7 & 0,024 & 489 & $130,0 \%$ & $152,2 \%$ & $55,6 \%$ & $17,1 \%$ & $49,4 \%$ \\
\hline TF29_Ele & 0,0 & 17,6 & 6 & 0,3 & 0,0 & 0,0 & 282,59 & 77,4 & 7,4 & 0,015 & 141 & 0,0 & 39,5 & $7,3 \%$ & 0,7 & 0,0 & 0,3 & 538,7 & 130,6 & 10,2 & 0,019 & 224 & & $68,7 \%$ & $38,0 \%$ & $22,3 \%$ & $58,9 \%$ \\
\hline TF30_Elec_distr_contr_wire_c & 0,0 & 35,1 & $4,4 \%$ & 1,0 & 0,0 & 0,3 & 794,46 & 49,4 & 6,3 & 0,014 & 231 & 0,0 & 41,6 & $4,3 \%$ & 1,2 & 0,0 & 0,6 & 958,0 & 47,9 & 6,1 & 0,011 & 281 & $93,7 \%$ & $-2,9 \%$ & $-3,6 \%$ & $-16,4 \%$ & $21,7 \%$ \\
\hline TF31_Accumulators_battery & 0,0 & 10,5 & $8,3 \%$ & 0,2 & 0,0 & 0,0 & 127,16 & 140,3 & 9,4 & 0,018 & 96 & 0,0 & 21,5 & $6,4 \%$ & 0,4 & 0,0 & 0,2 & 338,1 & 94,3 & 8,5 & 0,016 & 180 & 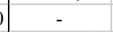 & $-32,8 \%$ & $-10,3 \%$ & $-10,4 \%$ & $88,2 \%$ \\
\hline TF32_Lighting_equipment & 0,0 & 14,1 & $8,3 \%$ & 0,2 & 0,0 & 0,0 & 169,38 & 148,3 & 10,1 & 0,018 & 108 & 0,0 & 29,7 & $8,2 \%$ & 0,4 & 0,0 & 0,2 & 361,4 & 135,8 & 9,9 & 0,019 & 163 & - & $-8,4 \%$ & $-1,6 \%$ & $3,9 \%$ & $50,5 \%$ \\
\hline TF33_Other_electr_equip & 0,0 & 36,7 & $6,0 \%$ & 0,7 & 0,0 & 0,3 & 609,64 & 91,2 & 8,1 & 0,014 & 218 & 0,0 & 46,6 & $5,2 \%$ & 1,1 & 0,0 & 0,7 & 899,5 & 82,9 & 7,8 & 0,012 & 313 & $98,1 \%$ & $-9,1 \%$ & $-3,6 \%$ & $-17,6 \%$ & $43,6 \%$ \\
\hline TF34_Electr_components & 0,0 & 132,3 & $\begin{array}{ll}3 & 11,8 \% \\
\end{array}$ & 1,4 & $\begin{array}{l}3,0 \\
+4\end{array}$ & 0,3 & 1121,12 & 199,3 & 12,7 & 0,033 & 245 & 0,0 & 182,1 & $9,5 \%$ & 2,4 & 0,0 & 0,9 & 1925,7 & 169,2 & 11,6 & 0,023 & 371 & $182,3 \%$ & $-15,1 \%$ & $-8,5 \%$ & $-28,7 \%$ & $51,3 \%$ \\
\hline TF35_Si & 0,0 & 160,1 & $7,7 \%$ & 2,6 & 50,0 & 0,9 & 2092,76 & 106,3 & 9,1 & 0, & 326 & 0,0 & 338,5 & $6,5 \%$ & 6,4 & 0,1 & 2,3 & 5222,7 & 92,5 & 8,5 & 0,0 & 486 & $152,0 \%$ & $-13,0 \%$ & $-7,5 \%$ & $-17,1 \%$ & $48,8 \%$ \\
\hline TF36_TV_radio_receiv_au & 0,0 & 69,5 & \begin{tabular}{l|l}
5 & $10,6 \%$ \\
\end{tabular} & 0,8 & 0,0 & 0,2 & 655,36 & 176,5 & 11,6 & 0,027 & 181 & 0,0 & 211,5 & $5 \quad 15,4 \%$ & 1,7 & 0,0 & 0,4 & 1374,0 & 377,9 & 17,2 & 0,036 & 272 & $72,6 \%$ & $114,1 \%$ & $48,1 \%$ & $32,6 \%$ & $50,6 \%$ \\
\hline TF37_Med_equipment & 0,0 & 53,2 & $3,2 \%$ & 2,0 & 0,0 & 1,2 & 1667,52 & 38,6 & 5,3 & 0,008 & 388 & 0,0 & 115,8 & $3,2 \%$ & 4,4 & 0,2 & 2,9 & 3611,6 & 34,9 & 4,9 & 0,007 & 510 & $116,8 \%$ & $-9,5 \%$ & $-7,5 \%$ & $-13,4 \%$ & $31,4 \%$ \\
\hline TF38_Measuring_instruments & 0,0 & 89,9 & $4,4 \%$ & 2,5 & 0,0 & 1,3 & 2031,89 & 59,7 & 6,5 & 0,010 & 382 & 0,0 & 175,8 & $4,9 \%$ & 4,4 & 0,1 & 2,4 & 3605,3 & 82,8 & 7,4 & 0,010 & 489 & $70,1 \%$ & $38,6 \%$ & $13,6 \%$ & $-3,5 \%$ & $27,9 \%$ \\
\hline TF39_In & 0 & 19,2 & 5 & 0,5 & 0,0 & 0,2 & 374,73 & 73,4 & 7,3 & 0,013 & 180 & 0,0 & 52,8 & $7,8 \%$ & 0,8 & 0,0 & 0,3 & 674,7 & 163,7 & 11,0 & 0,017 & 255 & $100,0 \%$ & $122,9 \%$ & $51,3 \%$ & $33,1 \%$ & $41,9 \%$ \\
\hline TF40_Opti_i & 0,0 & 48,9 & $5,4 \%$ & 1,1 & 0,0 & 0,5 & 903,10 & 68,6 & 7,3 & 0,014 & 257 & 0,0 & 170,5 & $5 \quad 12,2 \%$ & 1,7 & 0,0 & 0,7 & 1399,9 & 370,2 & 16,8 & 0,023 & 324 & $47,8 \%$ & $439,4 \%$ & $131,3 \%$ & $63,4 \%$ & $26,1 \%$ \\
\hline TF41_Watches_clocks & 0,0 & 8,4 & $\begin{array}{l}4 \quad 10,3 \% \\
\end{array}$ & 0,1 & 0,0 & 0,0 & 81,79 & 112,8 & 9,6 & 0,037 & 47 & 0,0 & 23,5 & $5 \quad 15,0 \%$ & 0,2 & 0,0 & 0,0 & 157,1 & 193,2 & 12,8 & 0,057 & 60 & & $71,3 \%$ & $33,6 \%$ & $56,3 \%$ & $26,1 \%$ \\
\hline TF42_Motor_vehicles & 0,0 & 251,8 & 9,7 & 3,2 & 0,0 & 1,5 & 2582,51 & 263,3 & 13,7 & 0 , & 391 & 0,0 & 732,9 & $9 \quad 13,2 \%$ & 6,8 & 0,3 & 3,0 & 5571,6 & 412,4 & 18,0 & 0,025 & 501 & $80,0 \%$ & $56,6 \%$ & $30,9 \%$ & $41,3 \%$ & $27,9 \%$ \\
\hline TF43_Other_tr & 0,0 & 24,3 & $3,8 \%$ & 0,8 & $\begin{array}{ll}3 & 0,0 \\
r\end{array}$ & 0,5 & 637,57 & 44,2 & 5,3 & 0,008 & 259 & 0,0 & 44,3 & $4,1 \%$ & 1,3 & 0,0 & 1,0 & 1078,8 & 61,1 & 6,4 & 0,008 & 353 & $92,2 \%$ & $38,3 \%$ & $19,5 \%$ & $2,6 \%$ & $36,2 \%$ \\
\hline TF44_Fu & 0,0 & 23,2 & $3,0 \%$ & 1,0 & 0,0 & 0,7 & 780,29 & 38,0 & 5,3 & 0,008 & 288 & 0,0 & 32,7 & $2,6 \%$ & 1,6 & 0,0 & 1,3 & 1274,1 & 30,3 & 4,7 & 0,006 & 379 & $100,0 \%$ & $-20,1 \%$ & $-10,5 \%$ & $-17,1 \%$ & $1,4 \%$ \\
\hline SUM_hightech & 0,0 & 287,3 & $7,1 \%$ & 4,9 & 0,0 & 1,8 & 4044,90 & 113,6 & 9,3 & 0,017 & 435 & 0,0 & 654,9 & $6,1 \%$ & 13,0 & 0,4 & 5,1 & 10672,1 & 110,7 & 9,0 & 0,015 & 594 & $157,2 \%$ & $-2,5 \%$ & $-3,1 \%$ & $-13,1 \%$ & $36,7 \%$ \\
\hline & 0,0 & 12,1 & 7,3 & 0,2 & 0,0 & 0,0 & 165,94 & 77,9 & 7,9 & 0, & 92 & 0,0 & 40,2 & $12,8 \%$ & 0,4 & 0,0 & 0,1 & 314,8 & 297,2 & 15,0 & 0,028 & 146 & & $281,6 \%$ & $89,5 \%$ & $21,1 \%$ & $59,3 \%$ \\
\hline HT2_Computer_office_mach & 0,0 & 78,1 & 8,0 & 1,2 & 0,0 & 0,4 & & 124,8 & 9,9 & 0 , & 244 & 0,0 & 251,0 & $8,2 \%$ & 3,7 & 0,0 & 1,4 & 3067,2 & 156,0 & 10,6 & 0 , & 419 & $244,7 \%$ & $25,0 \%$ & $7,2 \%$ & $-17,6 \%$ & $71,6 \%$ \\
\hline HT3_Laser & 0,0 & 16,8 & \begin{tabular}{l|l}
$8 \quad 12,3 \%$ \\
\end{tabular} & 0,2 & 0,0 & 0,0 & 136,82 & 151,3 & 11,3 & 0,044 & 72 & 0,0 & 10,1 & $6,4 \%$ & 0,2 & 0,0 & 0,0 & 157,3 & 63,3 & 7,0 & 0,020 & 101 & - & $-58,1 \%$ & $-38,3 \%$ & $-55,3 \%$ & $40,1 \%$ \\
\hline HT4_Semico & 0,0 & 63,1 & $1 \quad 10,7 \%$ & 0,7 & 0,0 & 0,1 & 589,52 & 153,6 & 11,2 & 0,033 & 168 & 0,0 & 106,9 & $9,0 \%$ & 1,4 & 0,0 & 0,4 & 1184,2 & 142,7 & 10,9 & 0,027 & 294 & $285,5 \%$ & $-7,1 \%$ & $-2,3 \%$ & $-18,7 \%$ & $5,0 \%$ \\
\hline HTS_C & 0,0 & 119,0 & $7,3 \%$ & 2,0 & 0,0 & 0,5 & 1639,44 & 96,2 & 8,9 & 0,022 & 275 & 0,0 & 322,7 & $6,5 \%$ & 6,0 & 0,0 & 1,7 & 4950,5 & 98,7 & 8,9 & 0,020 & 447 & $214,5 \%$ & $2,6 \%$ & $0,5 \%$ & $-9,1 \%$ & $2,5 \%$ \\
\hline HT6_Microorgan_Genetics & 0,0 & 38,5 & $3,4 \%$ & 1,4 & $+0,0$ & 0,5 & 1128,19 & 30,6 & 4,9 & 0,011 & 312 & 0,0 & 71,9 & $3,4 \%$ & 2,6 & 0,0 & 1,0 & 2125,0 & 36,9 & 5,2 & 0,010 & 391 & $95,8 \%$ & $20,6 \%$ & $5,9 \%$ & $-7,1 \%$ & $25,4 \%$ \\
\hline
\end{tabular}

Source: own illustration. Notes: The relational database covers 819 OECD Territorial Levels TL3 micro regions. For Belgium, Greece and the Netherlands, the

OECD TL3 corresponds to the EUROSTAT NUTS2 level. For Germany, we make use of 97 "Raumordnungsregionen". EPO patent application counting is based on fractional counting method. IDs are counted several times if inventor IDs correspond to several technology fields. 
Table 5: Descriptives: EPO Inventors (full counting of inventor IDs) by Technology Field

\begin{tabular}{|c|c|c|c|c|c|c|c|c|c|c|c|c|c|c|c|c|c|c|c|c|c|c|c|c|c|c|c|}
\hline \multirow[b]{2}{*}{ TF Label } & \multicolumn{11}{|c|}{ 1990-1992 (mean value) } & \multicolumn{11}{|c|}{ 2002-2004 (mean value) } & \multicolumn{5}{|c|}{ \%change } \\
\hline & $\begin{array}{c}(1 \mathrm{a}) \min \\
\mathrm{nb}\end{array}$ & $\begin{array}{c}\text { (2a) } \max \\
\mathrm{nb}\end{array}$ & $\begin{array}{l}\text { (3a) max } \\
\text { reg share }\end{array}$ & $\begin{array}{c}(4 a) \\
\text { mean nb } \\
\end{array}$ & $\begin{array}{l}\text { (5a) } \\
\text { P30 } \\
\end{array}$ & \begin{tabular}{l|l}
$(6 a)$ & ( \\
P70 & \\
\end{tabular} & $\begin{array}{c}(7 \mathrm{a}) \text { total } \\
\text { nb }\end{array}$ & $\begin{array}{c}\text { (8a) kurt } \\
\mathrm{nb}\end{array}$ & $\begin{array}{c}(9 a) \text { skew } \\
\text { nb }\end{array}$ & \begin{tabular}{|c|c}
$(10 a)$ & 1 \\
HHI & 1 \\
\end{tabular} & \begin{tabular}{|l|l}
$\begin{array}{l}\text { (11a) regions } \\
\text { n>1 inventor }\end{array}$ \\
\end{tabular} & $\begin{array}{c}(1 b) \min \\
n b\end{array}$ & $\begin{array}{c}(2 b) \max \\
\mathrm{nb}\end{array}$ & $\begin{array}{l}\text { (3b) max } \\
\text { reg share }\end{array}$ & $\begin{array}{c}(4 \mathrm{~b}) \\
\text { mean nb }\end{array}$ & $\begin{array}{lll}(5 b) & (1 \\
\text { P30 } & \text { F } \\
\end{array}$ & \begin{tabular}{l|l|}
$(6 b)$ \\
P70
\end{tabular} & $\begin{array}{c}\text { (7b) total } \\
\text { nb }\end{array}$ & $\begin{array}{c}\text { (8b) kurt } \\
\mathrm{nb}\end{array}$ & $\begin{array}{c}(9 b) \\
\text { skew nb }\end{array}$ & $\begin{array}{c}(10 \mathrm{~b}) \\
\mathrm{HHI} \\
\end{array}$ & \begin{tabular}{|l|}
$\begin{array}{l}\text { (11b) regions } \\
n>1 \text { inventor }\end{array}$ \\
\end{tabular} & $\begin{array}{c}\Delta(\mathrm{P} 70-\mathrm{P} 30) \\
(6)-(5)\end{array}$ & $\Delta$ kurt (8) & $\begin{array}{c}\Delta \text { skew } \\
(9)\end{array}$ & $\begin{array}{c}\Delta \mathrm{HHI} \\
(10)\end{array}$ & \begin{tabular}{|c|c|}
$\begin{array}{c}\Delta \text { regions } \\
n>1 \text { inventor } \\
(11)\end{array}$ \\
\end{tabular} \\
\hline SUM_44_TF & 0,0 & 1730,0 & $3,2 \%$ & 65,7 & 3,0 & 39,9 & 53847,0 & 45,5 & 6,0 & 0,009 & 609 & 0,0 & 3637,7 & $3,4 \%$ & 130,5 & 9,5 & 77,5 & 106866,0 & 50,8 & 5,9 & 0,008 & 717 & $84,6 \%$ & $11,6 \%$ & $-1,0 \%$ & $-16,3 \%$ & $17,8 \%$ \\
\hline TF1_Food_beverages & 0,0 & 84,3 & $7,8 \%$ & 1,3 & 0,0 & 0,7 & 1085,7 & 184,1 & 11,0 & 0,014 & 155 & 0,0 & 94,7 & $4,9 \%$ & 2,4 & 0,0 & 1,3 & 1925,3 & 65,6 & 6,8 & 0,011 & 216 & $100,0 \%$ & $-64,4 \%$ & $-38,4 \%$ & $-21,7 \%$ & $39,6 \%$ \\
\hline TF2_Tobacco_prod & 0,0 & 12,0 & $18,3 \%$ & 0,1 & 0,0 & 0,0 & 65,7 & 330,8 & 16,5 & \begin{tabular}{|l|}
0,057 \\
\end{tabular} & 12 & 0,0 & 28,0 & $22,0 \%$ & 0,2 & 0,0 & 0,0 & 127,3 & 320,2 & 17,1 & 0,095 & 17 & & $-3,2 \%$ & $3,3 \%$ & $68,6 \%$ & $40,5 \%$ \\
\hline TF3_Textiles & 0,0 & 65,3 & $8,7 \%$ & 0,9 & 0,0 & 0,3 & 752,7 & 129,3 & 10,5 & 0,027 & 98 & 0,0 & 39,3 & $5,4 \%$ & 0,9 & 0,0 & 0,3 & 723,3 & 76,9 & 7,5 & 0,014 & 110 & $0,0 \%$ & $-40,5 \%$ & $-28,7 \%$ & $-50,7 \%$ & $11,9 \%$ \\
\hline TF4_Wearing_apparel & 0,0 & 2,7 & $4,7 \%$ & 0,1 & 0,0 & 0,0 & 56,3 & 45,5 & 6,0 & 0,018 & 12 & 0,0 & 6,7 & $3,7 \%$ & 0,2 & 0,0 & 0,0 & 180,3 & 36,6 & 5,3 & 0,011 & 39 & & $-19,6 \%$ & $-12,3 \%$ & $-36,5 \%$ & $227,8 \%$ \\
\hline TF5_Leather_articles & 0,0 & 28,7 & $25,4 \%$ & 0,1 & 0,0 & 0,0 & 113,0 & 546,9 & 22,0 & 0,080 & 16 & 0,0 & 29,3 & $15,7 \%$ & 0,2 & 0,0 & 0,0 & 187,0 & 382,2 & 17,6 & 0,037 & 29 & - & $-30,1 \%$ & $-19,9 \%$ & $-53,1 \%$ & $75,5 \%$ \\
\hline TF6_Wood_prod & 0,0 & 8,7 & $4,4 \%$ & 0,2 & 0,0 & 0,0 & 196,7 & 49,3 & 5,6 & $\mid 0,010$ & 47 & 0,0 & 7,7 & $2,9 \%$ & 0,3 & 0,0 & 0,3 & 266,0 & 22,9 & 4,1 & 0,008 & 60 & & $-53,5 \%$ & $-27,2 \%$ & $-24,0 \%$ & $27,0 \%$ \\
\hline TF7_Paper & 0,0 & 44,7 & $5,4 \%$ & 1,0 & 0,0 & 0,3 & 823,0 & 74,2 & 7,6 & 0,015 & 118 & 0,0 & 47,0 & $4,1 \%$ & 1,4 & 0,0 & 0,7 & 1160,0 & 43,6 & 5,7 & 0,010 & 156 & $100,0 \%$ & $-41,3 \%$ & $-26,0 \%$ & $-32,1 \%$ & $32,6 \%$ \\
\hline TF9_Petrol_prod_nucl_fuel & 0,0 & 30,0 & $6,0 \%$ & 0,6 & 5,0 & 0,0 & 497,0 & 72,6 & 7,8 & 0,021 & 74 & 0,0 & 51,7 & $6,9 \%$ & 0,9 & 0,0 & 0,3 & 745,3 & 103,3 & 8,5 & 0,016 & 107 & & $42,4 \%$ & $8,7 \%$ & $-24,2 \%$ & $44,8 \%$ \\
\hline TF10_Basic_chemical & 0,0 & 668,0 & $6,2 \%$ & 13,2 & $2 \quad 0,3$ & 5,7 & 10803,0 & 111,2 & 9,7 & 0,019 & 389 & 0,0 & 553,3 & $4,5 \%$ & 15,0 & 0,7 & 8,3 & 12260,0 & 70,8 & 7,4 & 0,011 & 459 & $43,8 \%$ & $-36,4 \%$ & $-23,6 \%$ & $-40,0 \%$ & $17,9 \%$ \\
\hline TF11_Pesticide_agr & 0,0 & 116,0 & $\quad 10,9 \%$ & 1,3 & 0,0 & 0,3 & 1061,3 & 156,6 & 11,9 & 0,047 & 92 & 0,0 & 108,3 & $10,8 \%$ & 1,2 & 0,0 & 0,3 & 1007,3 & 129,1 & 10,8 & 0,041 & 103 & $0,0 \%$ & $-17,6 \%$ & $-9,2 \%$ & $-11,2 \%$ & $12,4 \%$ \\
\hline TF12_Paints_varnishes & 0,0 & 12,3 & $19,9 \%$ & 0,1 & 0,0 & 0,0 & 62,0 & 341,1 & 16,5 & 0,063 & 11 & 0,0 & 4,3 & $9,0 \%$ & 0,1 & 0,0 & 0,0 & 48,3 & 96,6 & 8,2 & 0,027 & 13 & & $-71,7 \%$ & $-50,0 \%$ & $-57,5 \%$ & $14,7 \%$ \\
\hline TF13_Pharmaceuticals & 0,0 & 386,3 & $4,4 \%$ & 10,7 & 0,0 & 3,5 & 8755,7 & 52,3 & 6,4 & 0,013 & 321 & 0,0 & 448,0 & $2,5 \%$ & 21,7 & 0,7 & 8,7 & 17735,3 & 22,1 & 4,4 & 0,009 & 456 & $126,4 \%$ & $-57,7 \%$ & $-32,0 \%$ & $-29,9 \%$ & $42,0 \%$ \\
\hline TF14_Soaps_detergents & 0,0 & 181,0 & $21,5 \%$ & 1,0 & 0,0 & 0,0 & 843,0 & 441,6 & 19,2 & 0,064 & 79 & 0,0 & 104,0 & $11,3 \%$ & 1,1 & 0,0 & 0,0 & 922,7 & 166,1 & 11,7 & 0,035 & 95 & & $-62,4 \%$ & $-38,9 \%$ & $-45,6 \%$ & $20,2 \%$ \\
\hline TF15_Other_chemicals & 0,0 & 128,0 & $7,7 \%$ & 2,0 & 0,0 & 0,7 & 1673,0 & 126,3 & 9,9 & 0,019 & 172 & 0,0 & 78,0 & $5,5 \%$ & 1,7 & 0,0 & 0,7 & 1427,0 & 83,8 & 7,8 & 0,013 & 178 & $0,0 \%$ & $-33,6 \%$ & $-21,1 \%$ & $-31,3 \%$ & $3,5 \%$ \\
\hline TF16_Man_made_fibre & 0,0 & 14,3 & $7,7 \%$ & 0,2 & 0,0 & 0,0 & 185,7 & 90,2 & 8,7 & 0,032 & 30 & 0,0 & 10,0 & $5,2 \%$ & 0,2 & 0,0 & 0,0 & 193,7 & 45,6 & 6,2 & 0,019 & 36 & & $-49,5 \%$ & $-28,9 \%$ & $-42,2 \%$ & $18,7 \%$ \\
\hline TF17_Ru & 0,0 & 100,0 & $2,8 \%$ & 4,4 & 0,0 & 3,2 & 3595,7 & 32,6 & 4,9 & 0,0 & 342 & 0,0 & 127,3 & $2,3 \%$ & 6,8 & 0,3 & 5,2 & 5566,3 & 26,1 & 4,4 & 0,006 & 415 & $52,1 \%$ & $-19,8 \%$ & $-9,7 \%$ & $-13,6 \%$ & $21,1 \%$ \\
\hline TF18_Non-metal_mineral_prod & 0,0 & 131,0 & $5,0 \%$ & 3,2 & 0,0 & 2,2 & 2635,7 & 79,6 & 7,1 & 0,009 & 276 & 0,0 & 108,7 & $3,0 \%$ & 4,4 & 0,3 & 3,0 & 3635,7 & 33,4 & 4,8 & 0,007 & 342 & $21,2 \%$ & $-58,0 \%$ & $-32,6 \%$ & $-28,3 \%$ & $24,1 \%$ \\
\hline TF19_Basic_metals & 0,0 & 90,0 & $4,7 \%$ & 2,3 & 0,0 & 1,3 & 1897,0 & 75,9 & 7,4 & 0,011 & 218 & 0,0 & 97,0 & $4,2 \%$ & 2,8 & 0,0 & 1,7 & 2304,0 & 60,8 & 6,5 & 0,009 & 264 & $25,0 \%$ & $-19,8 \%$ & $-11,6 \%$ & $-17,9 \%$ & $21,1 \%$ \\
\hline TF20_Fabric_metal_prod & 0,0 & 113,0 & $4,3 \%$ & 3,2 & 0,0 & 2,3 & 2633,3 & 75,3 & 7,3 & 0,009 & 287 & 0,0 & 207,0 & $4,7 \%$ & 5,3 & 0,3 & 4,0 & 4380,3 & 94,7 & 7,9 & 0,008 & 382 & $57,1 \%$ & $25,8 \%$ & $9,0 \%$ & $-7,9 \%$ & $33,4 \%$ \\
\hline TF21 Energy_machinery & 0,0 & 164,0 & $6,5 \%$ & 3,1 & 0,0 & 1,7 & 2522,3 & 127,2 & 9,1 & 0,012 & 252 & 0,0 & 363,7 & $6,5 \%$ & 6,9 & 0,3 & 3,9 & 5634,7 & 120,4 & 9,0 & 0,012 & 342 & $112,0 \%$ & $-5,3 \%$ & $-1,3 \%$ & $2,1 \%$ & $35,7 \%$ \\
\hline TF22_Non & 0,0 & 148,7 & $3,8 \%$ & 4,8 & 0,0 & 3,0 & 3912,3 & 56,8 & 6,4 & 0,0 & 336 & 0,0 & 426,7 & $7,5 \%$ & 7,0 & 0,3 & 5,0 & 5726,3 & 265,6 & 13,3 & & 396 & $55,6 \%$ & $367,4 \%$ & $107,1 \%$ & $21,6 \%$ & $8,0 \%$ \\
\hline TF23_As & 0,0 & 30,0 & $3,9 \%$ & 0,9 & 0,0 & 0,7 & 761,0 & 55,2 & 6,0 & 0, & 144 & 0,0 & 49,7 & $3,8 \%$ & 1,6 & 0,0 & 1,0 & 3177 & 55,5 & 6,4 & & 201 & $50,0 \%$ & $0,5 \%$ & $5,9 \%$ & $5,4 \%$ & $9,9 \%$ \\
\hline TF24_Machine_tools & 0,0 & 180,3 & $8,8 \%$ & 2,5 & 0,0 & 1,3 & 2051,3 & 287,3 & 14,1 & \begin{tabular}{|l|}
0,014 \\
0
\end{tabular} & 235 & 0,0 & 237,0 & $7,5 \%$ & 3,8 & 0,0 & 2,3 & 3146,0 & 222,1 & 12,0 & 0,012 & 290 & $75,0 \%$ & $-22,7 \%$ & $-14,7 \%$ & $-15,0 \%$ & $23,7 \%$ \\
\hline TF25_Spec_purp_machinery & 0,0 & 305,0 & $5,1 \%$ & 7,2 & 0,0 & 4,7 & 5929,3 & 93,0 & 7,9 & 0,010 & 385 & 0,0 & 244,7 & $3,0 \%$ & 9,8 & 0,3 & 6,7 & 8057,3 & 35,5 & 5,0 & 0,007 & 438 & $35,7 \%$ & $-61,9 \%$ & $-36,0 \%$ & $-23,9 \%$ & $13,6 \%$ \\
\hline TF26_Weapons_ammunition & 0,0 & 17,7 & $7,0 \%$ & 0,3 & 0,0 & 0,0 & 254,0 & 92,8 & 8,5 & 0,021 & 45 & 0,0 & 15,7 & $4,8 \%$ & 0,4 & 0,0 & 0,0 & 324,7 & 55,3 & 6,9 & 0,018 & 56 & & $-40,4 \%$ & $-18,9 \%$ & $-13,2 \%$ & $23,7 \%$ \\
\hline TF27 Domestic appliances & 0,0 & 55,7 & $3,7 \%$ & 1,9 & 0,0 & 1,0 & 1518,3 & 43,4 & 5,7 & 0,010 & 201 & 0,0 & 133,7 & $4,0 \%$ & 4,0 & 0,0 & 2,7 & 3305,0 & 60,8 & 6,8 & 0,010 & 302 & $166,7 \%$ & $40,3 \%$ & $17,8 \%$ & $3,8 \%$ & $50,2 \%$ \\
\hline TF28_Off & 0,0 & 281,7 & $8,0 \%$ & 4,3 & 0,0 & 1,7 & 3522,3 & 129,8 & 10,0 & 0,0 & 234 & 0,0 & 854,0 & $9,3 \%$ & 11,2 & 0,3 & 5,0 & 9179,0 & 216,8 & 12,5 & & 393 & $180,0 \%$ & $7,0 \%$ & $24,1 \%$ & $-11,6 \%$ & $8,0 \%$ \\
\hline TF29_Electric_motors_generators & 0,0 & 39,0 & $7,7 \%$ & 0,6 & 0,0 & 0,0 & 504,7 & 116,4 & 8,9 & 0,018 & 83 & 0,0 & 83,7 & $7,8 \%$ & 1,3 & 0,0 & 0,7 & 1077,7 & 156,3 & 11,1 & 0,020 & 144 & & $34,2 \%$ & $24,4 \%$ & $14,2 \%$ & $73,2 \%$ \\
\hline TF30_Elec_distr_contr_wire_cable & 0,0 & 89,0 & $6,5 \%$ & 1,7 & 0,0 & 0,7 & 1360,0 & 84,7 & 8,0 & 0,017 & 149 & 0,0 & 82,3 & $4,4 \%$ & 2,3 & 0,0 & 1,0 & 1851,3 & 49,8 & 6,3 & 0,012 & 198 & $50,0 \%$ & $-41,2 \%$ & $-21,3 \%$ & $-26,0 \%$ & $33,1 \%$ \\
\hline TF31_Accumulators_battery & 0,0 & 21,3 & $8,3 \%$ & 0,3 & 0,0 & 0,0 & 258,0 & 133,3 & 9,3 & 0,018 & 52 & 0,0 & 48,3 & $5,7 \%$ & 1,0 & 0,0 & 0,3 & 842,7 & 80,5 & 8,0 & 0,016 & 118 & - & $-39,7 \%$ & $-14,0 \%$ & $-11,2 \%$ & $129,0 \%$ \\
\hline TF32_Lighting_equipment & 0,0 & 23,0 & $8,7 \%$ & 0,3 & 0,0 & 0,0 & 265,7 & 153,5 & 10,3 & 0,0 & 51 & 0,0 & 59,3 & $9,3 \%$ & 0,8 & 0,0 & 0,3 & 638,0 & 160,1 & 11,0 & 0,022 & 93 & & $4,3 \%$ & $6,6 \%$ & $17,3 \%$ & $81,8 \%$ \\
\hline TF33 Other el & 0,0 & 77,7 & $7,3 \%$ & 1,3 & 0,0 & 0,7 & 1062,0 & 120,7 & 9,2 & 0,0 & 143 & 0,0 & 103,7 & $5, \%$ & 2,1 & 0,0 & 1,3 & 1757,0 & 102,5 & 8,5 & 0,012 & 217 & $100,0 \%$ & $-15,1 \%$ & $-7,2 \%$ & $-23,5 \%$ & $51,9 \%$ \\
\hline TF34_El & 0,0 & 265,0 & $12,0 \%$ & 2,7 & 0,0 & 0,7 & 2216,7 & 198,6 & 12,6 & 0,0 & 173 & 0,0 & 442,3 & $9,8 \%$ & 5,5 & 0,0 & 2,0 & 4515,0 & 185,9 & 12,0 & 0, & 279 & $200,0 \%$ & $-6,4 \%$ & $-4,8 \%$ & $-30,4 \%$ & $61,4 \%$ \\
\hline TF35_Signal_transm_telecom & 0,0 & 260,0 & $7,2 \%$ & 4,4 & $\begin{array}{r}+, 0 \\
+\quad 0,0\end{array}$ & 1,3 & 3624,3 & 96,9 & 8,8 & 0,0 & 238 & 0,0 & 595,7 & $5,8 \%$ & 12,5 & 0,3 & 5,0 & 10265,3 & 81,6 & 7,9 & 0,015 & 383 & $250,0 \%$ & $-15,8 \%$ & $-9,9 \%$ & $-22,5 \%$ & $61,1 \%$ \\
\hline TF36_TV_radio_receiv_aud & 0,0 & 129,7 & $12,1 \%$ & 1,3 & 0,0 & 0,3 & 1073,3 & 210,9 & 12,8 & 0,0 & 108 & 0,0 & 356,3 & $13,8 \%$ & 3,2 & 0,0 & 1,0 & 2590,7 & 322,7 & 15,7 & 0,031 & 185 & $200,0 \%$ & $53,0 \%$ & $22,4 \%$ & $-1,1 \%$ & $70,8 \%$ \\
\hline TF37_Med_equipment & 0,0 & 82,3 & $2,8 \%$ & 3,6 & 0,0 & 2,3 & 2936,0 & 31,0 & 4,9 & 0,0 & 283 & 0,0 & 219,0 & $3,0 \%$ & 8,8 & 0,3 & 5,7 & 7221,7 & 33,1 & 4,9 & 0,007 & 416 & $128,6 \%$ & $6,9 \%$ & $1,2 \%$ & $-7,9 \%$ & $46,9 \%$ \\
\hline TF38_Measuring_instruments & 0,0 & 170,7 & $4,2 \%$ & 4,9 & 0,0 & 2,7 & 4016,7 & 56,4 & 6,4 & 0,010 & 299 & 0,0 & 381,7 & $4,6 \%$ & 10,0 & 0,3 & 5,7 & 8216,7 & 76,6 & 7,1 & 0,010 & 394 & $100,0 \%$ & $36,0 \%$ & $12,0 \%$ & $-6,8 \%$ & $31,7 \%$ \\
\hline TF39 Inc & 0,0 & 46,3 & $6,4 \%$ & 0,9 & 0,0 & 0,3 & 719,0 & 104,1 & 8,4 & 0,0 & 116 & 0,0 & 110,3 & $7,9 \%$ & 1,7 & 0,0 & 0,7 & 1401,7 & 184,7 & 11,9 & 0,018 & 162 & $100,0 \%$ & $77,5 \%$ & $42,0 \%$ & $29.5 \%$ & $39,9 \%$ \\
\hline TF40_O & 0,0 & 98,3 & $5,9 \%$ & 2,0 & 0,0 & 1,0 & 1667,0 & 73,6 & 7,7 & 0,0 & 174 & 0,0 & 436,0 & $14,4 \%$ & 3,7 & 0,0 & 1,3 & 3018,3 & 439 & 18,8 & & 233 & $33,3 \%$ & $496,8 \%$ & $144,0 \%$ & $76,0 \%$ & $33,8 \%$ \\
\hline TF41_Watches_cl & 0,0 & 11,0 & 9,6 & 0,1 & 0,0 & 0,0 & 114,3 & 10 & 9,1 & $0, \mathrm{c}$ & 22 & 0,0 & 37,0 & $15,9 \%$ & 0,3 & 0,0 & 0,0 & 23 & 226 & 13,4 & & 31 & & $119,0 \%$ & $48,4 \%$ & $56,4 \%$ & $0,3 \%$ \\
\hline TF42_Motor_vehicles & 0,0 & 527,0 & $12,1 \%$ & 5,3 & 0,0 & 2,0 & 4345,3 & 356,3 & 16,5 & 0, & 292 & 0,0 & 1406,7 & $13,7 \%$ & 12,6 & 0,3 & 5,0 & 10300,7 & 418,0 & 18,2 & 0,027 & 395 & $133,3 \%$ & $17,3 \%$ & $10,3 \%$ & $15,9 \%$ & $35,5 \%$ \\
\hline TF43_Other_transp_eq & 0,0 & 44,7 & $4,3 \%$ & 1,3 & 0,0 & 0,7 & 1034,0 & 57,7 & 6,0 & 0,009 & 154 & 0,0 & 78,0 & $4,3 \%$ & 2,2 & 0,0 & 1,3 & 1824,7 & 64,0 & 6,7 & 0,009 & 236 & $100,0 \%$ & $10,9 \%$ & $12,2 \%$ & $6,3 \%$ & $3,1 \%$ \\
\hline TF44 Furniture cons & 0,0 & 33,7 & $3,2 \%$ & 1,3 & 0,0 & 1,0 & 1050,3 & 41,9 & 5,5 & 0,008 & 176 & 0,0 & 48,0 & $2,6 \%$ & 2,2 & 0,0 & 2,0 & 1842,7 & 31,3 & 4,8 & 0,007 & 265 & $100,0 \%$ & $-25,4 \%$ & $-12,5 \%$ & $-18,1 \%$ & $0,1 \%$ \\
\hline SUM_- & 0,0 & 504,0 & $6,2 \%$ & 9,9 & 0,0 & 3,7 & 8074,3 & 9 & 8,4 & & 345 & 0,0 & 1173,0 & $5,1 \%$ & 27,9 & 1,0 & 11,3 & 22832,3 & 83,5 & 7,8 & 0,013 & 513 & $181,8 \%$ & $-10,1 \%$ & $-7,3 \%$ & $-16,4 \%$ &, $7 \%$ \\
\hline & 0,0 & 17 & & 0,3 & 0,0 & 0,0 & 2 & & 7,6 & 0, & 41 & 0, & 71,0 & 12,6 & 0,7 & 0,0 & 0,3 & 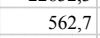 & 29 & 14,8 & & & & $328,1 \%$ & $96,2 \%$ & & $6,0 \%$ \\
\hline HT2 Computer_office mach & 0,0 & 137,7 & 8, & 2,1 & 0,0 & 0,7 & 17 & 112,2 & 9,4 & 0, & 162 & 0,0 & 437,0 & $7,0 \%$ & 7,6 & 0,0 & 3,0 & 620 & 117,6 & 9,2 & & 323 & 350,0 & & $-2,3 \%$ & $-27,5 \%$ & $99,4 \%$ \\
\hline HT3_Laser & 0,0 & 29,3 & $10,2 \%$ & 0,4 & 0,0 & 0,0 & 287,3 & 122,0 & 10,3 & \begin{tabular}{|l|}
0,041 \\
\end{tabular} & 41 & 0,0 & 28,7 & $7,5 \%$ & 0,5 & 0,0 & 0,0 & 383,0 & 95,8 & 8,3 & 0,020 & 59 & & $-21,5 \%$ & $-19,4 \%$ & $-50,2 \%$ & $43,1 \%$ \\
\hline HT4_Semiconductors & 0,0 & 111,0 & $9,3 \%$ & 1,5 & 0,0 & 0,3 & 1195,0 & 129,8 & 10,4 & 0,031 & 112 & 0,0 & 281,0 & $9,9 \%$ & 3,5 & 0,0 & 1,0 & 2843,7 & 164,9 & 11,5 & 0,026 & 205 & $200,0 \%$ & $27,0 \%$ & $10,9 \%$ & $-15,0 \%$ & $2,8 \%$ \\
\hline nication & 0,0 & 193,3 & $7,1 \%$ & 3,3 & 0,0 & 1,0 & 2713,0 & 99,2 & 9,0 & 0.022 & 189 & 0,0 & 541,7 & $5,7 \%$ & 11,6 & 0,3 & 3,3 & 9486,7 & 81,7 & 8,1 & 0.018 & 200 & $200,0 \%$ & $-17,6 \%$ & $-9,7 \%$ & $-20,2 \%$ & $3.8 \%$ \\
\hline HT6_Microorgan_Ge & 0,0 & 87,3 & $3,5 \%$ & 3,0 & 0,0 & 1,0 & 2485,0 & 31,5 & 5,1 & 012 & 200 & 0,0 & 231,3 & $4,6 \%$ & & 0,0 & & 5036,3 & 52,2 & 6,1 & & & $153,3 \%$ & $65,9 \%$ & $20,9 \%$ & $-3,5 \%$ & $44,5 \%$ \\
\hline
\end{tabular}

Source: own illustration. Notes: The relational database covers 819 OECD Territorial Levels TL3 micro regions. For Belgium, Greece and the Netherlands, the

OECD TL3 corresponds to the EUROSTAT NUTS2 level. For Germany, we make use of 97 "Raumordnungsregionen". Inventor counting is based on full counting method. IDs are counted several times if inventor IDs correspond to several technology fields. 
Figure 1: Share of Regions (\%) in Sample with $\mathrm{n}>0$ Patent Applications by Technology Field (fractional counting, 1977-2004)
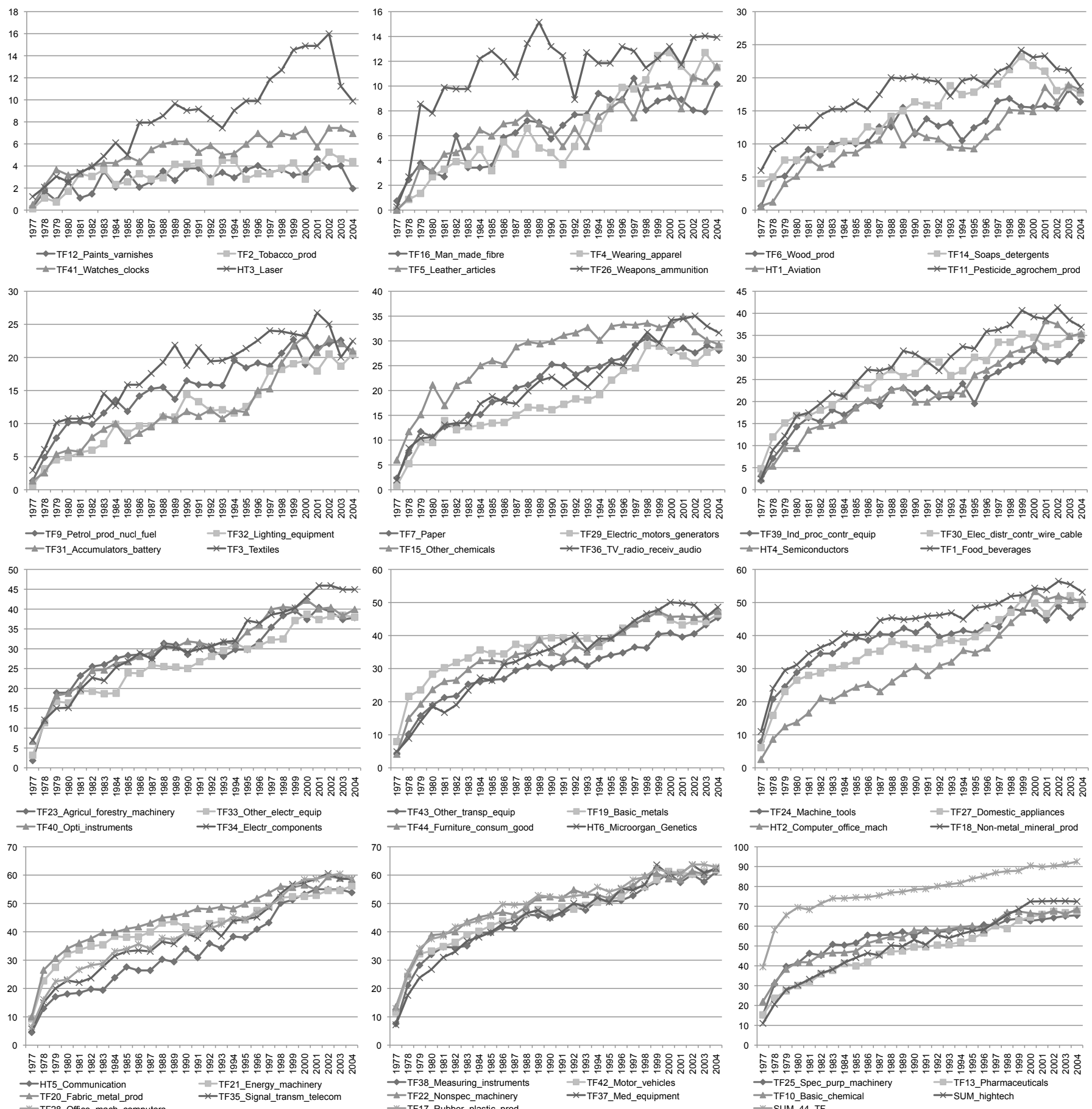

Source: own calculations and illustration. Notes: The sample covers 819 European TL3 micro regions. The patent data are generated by mySQL RegPAT (2009) database extractions and application of the ISI-SPRU-OST concordance. TL3 population data for the period 1988-2004 are constructed from EUROSTAT REGIO, OECD, ESPON and BBR data. For Belgium, Greece and the Netherlands, the OECD TL3 corresponds to the EUROSTAT NUTS2 level. For Germany, we make use of the "Raumordnungsregionen". 
Figure 2: Share of Regions (\%) in Sample with n > 9 Patent Applications by Technology Field (fractional counting, 1977-2004)
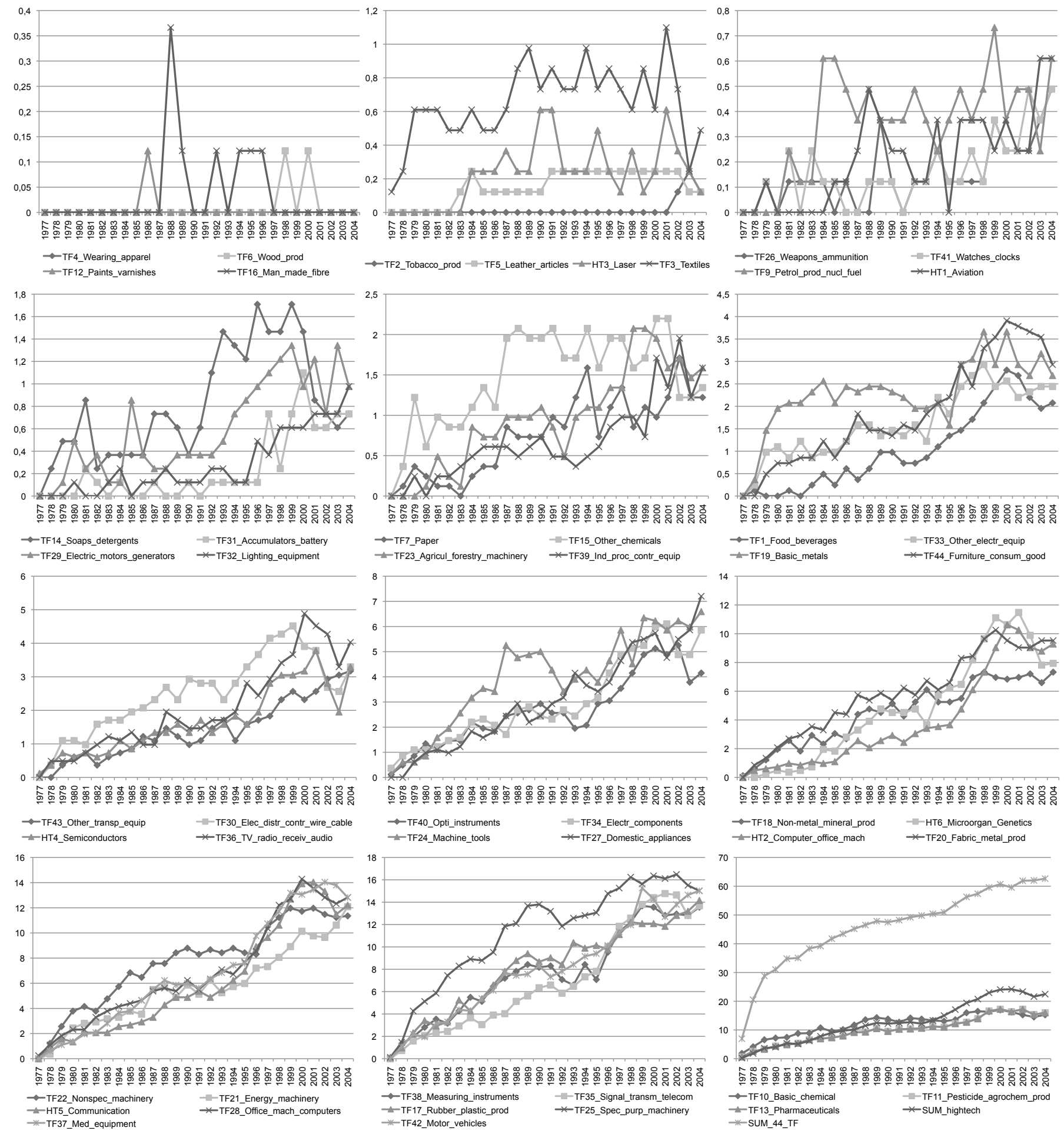

Source: own calculations and illustration. Notes: The sample covers 819 European TL3 micro regions. The patent data are generated by mySQL RegPAT (2009) database extractions and application of the ISI-SPRU-OST concordance. TL3 population data for the period 1988-2004 are constructed from EUROSTAT REGIO, OECD, ESPON and BBR data. For Belgium, Greece and the Netherlands, the OECD TL3 corresponds to the EUROSTAT NUTS2 level. For Germany, we make use of the "Raumordnungsregionen". 
Figure 3: Share of Regions (\%) in Sample with $\mathrm{n}>9$ Inventor IDs by Technology Field (full counting, 1977-2004)
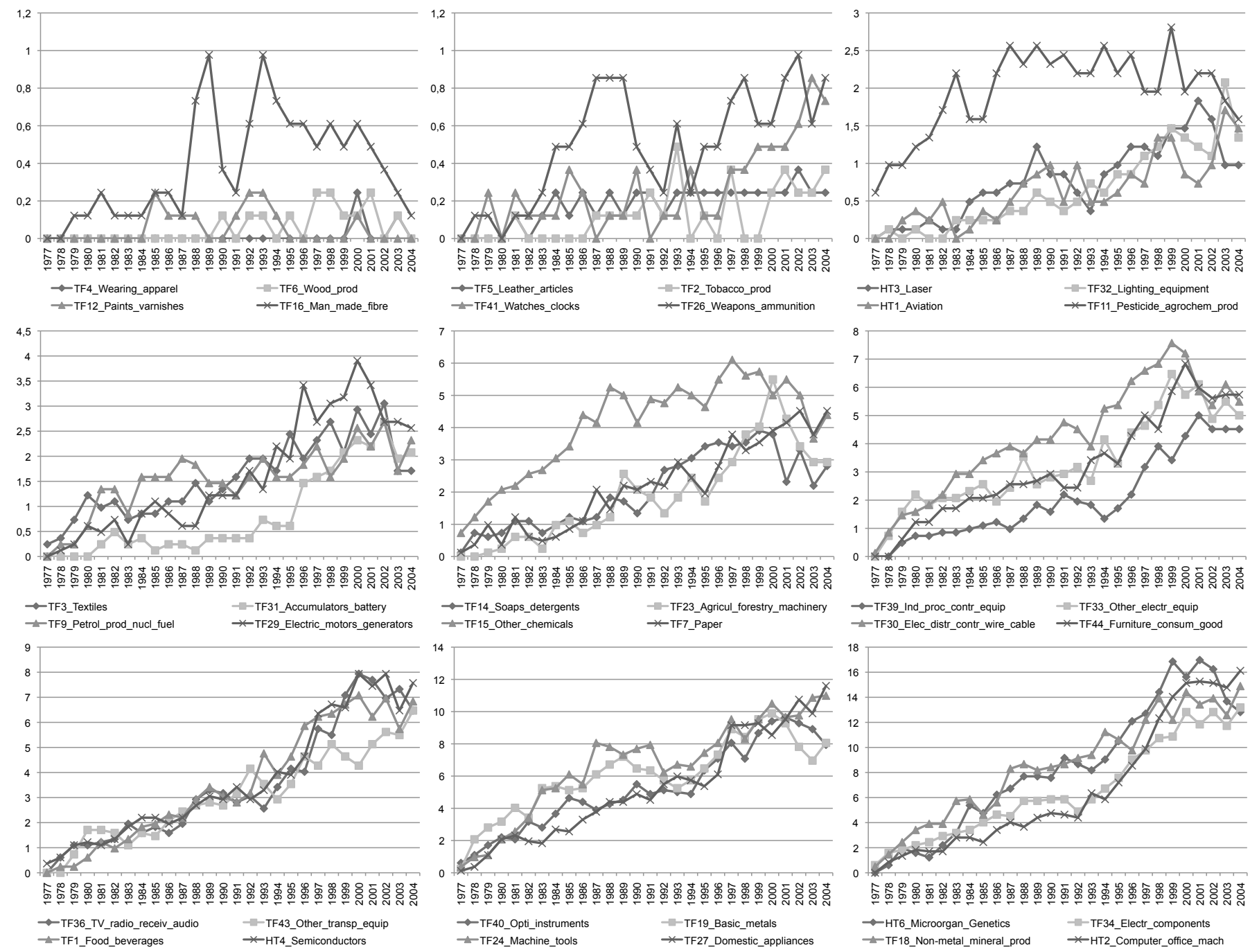

$$
\leadsto \text { TF15_Other_chemicals } \quad \text { *TF7_Paper }
$$
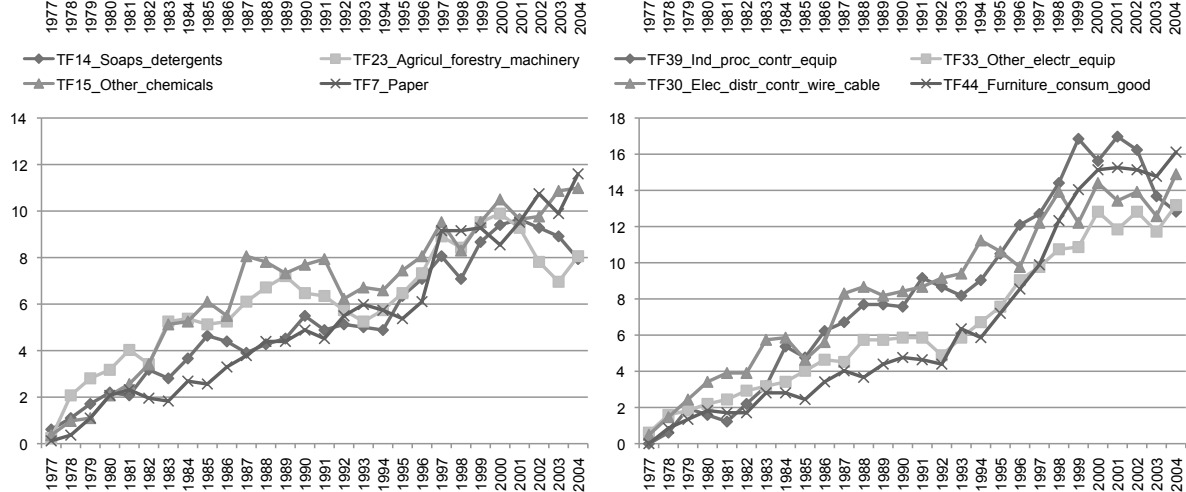

$\rightarrow$ TF39_Ind_proc_contr_equip $\quad-$ TF33_Other_electr_equip -TF30_Elec_distr_contr_wire_cable *TF44_Furniture_consum_good
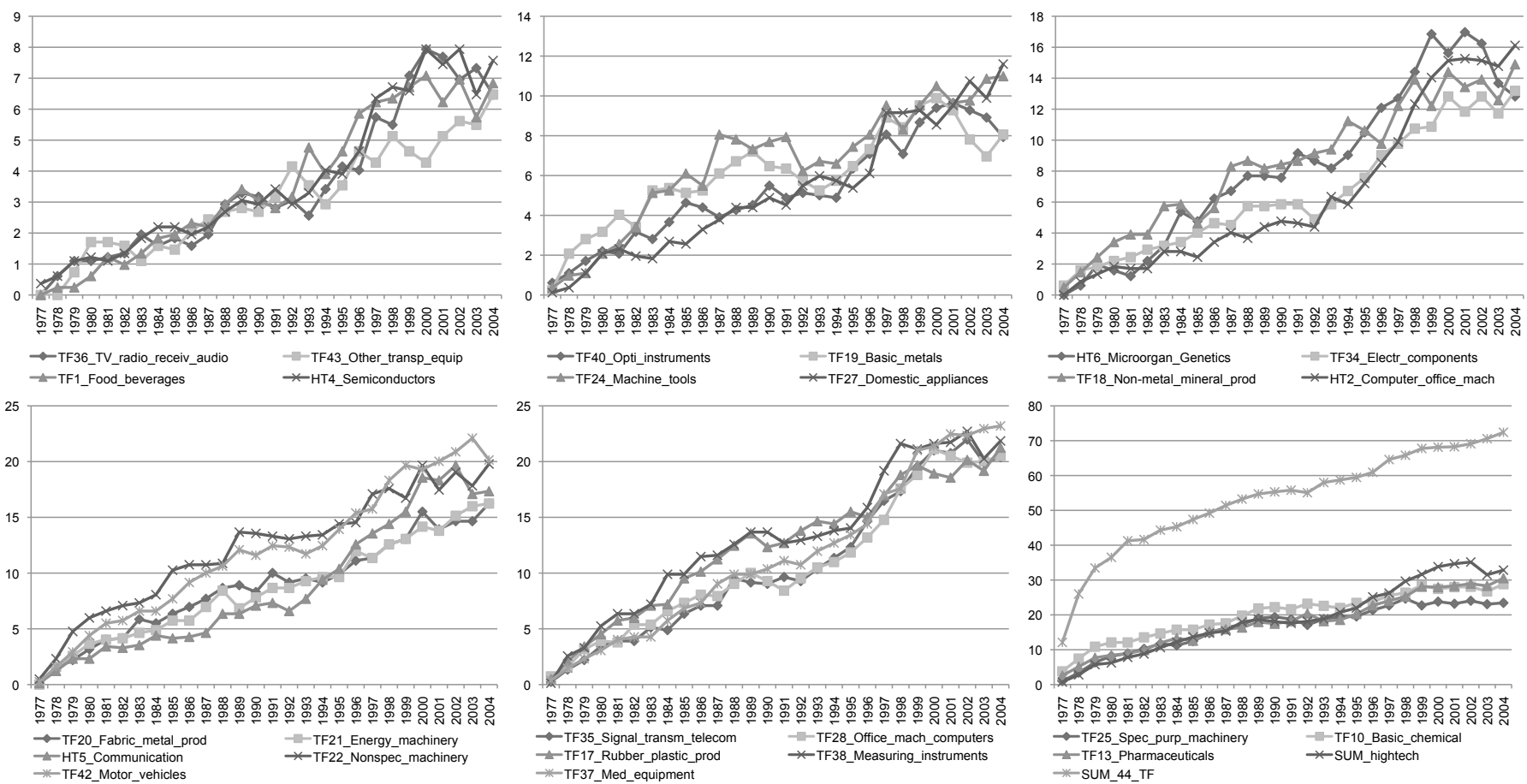

Source: own calculations and illustration. Notes: The sample covers 819 European TL3 micro regions. The patent data are generated by mySQL RegPAT (2009) database extractions and application of the ISI-SPRU-OST concordance. TL3 population data for the period 1988-2004 are constructed from EUROSTAT REGIO, OECD, ESPON and BBR data. For Belgium, Greece and the Netherlands, the OECD TL3 corresponds to the EUROSTAT NUTS2 level. For Germany, we make use of the "Raumordnungsregionen". 
Figure 4: Share of Regions (\%) in Sample with LQ > 1 (patent applications) by Technology

Field (1977-2004)
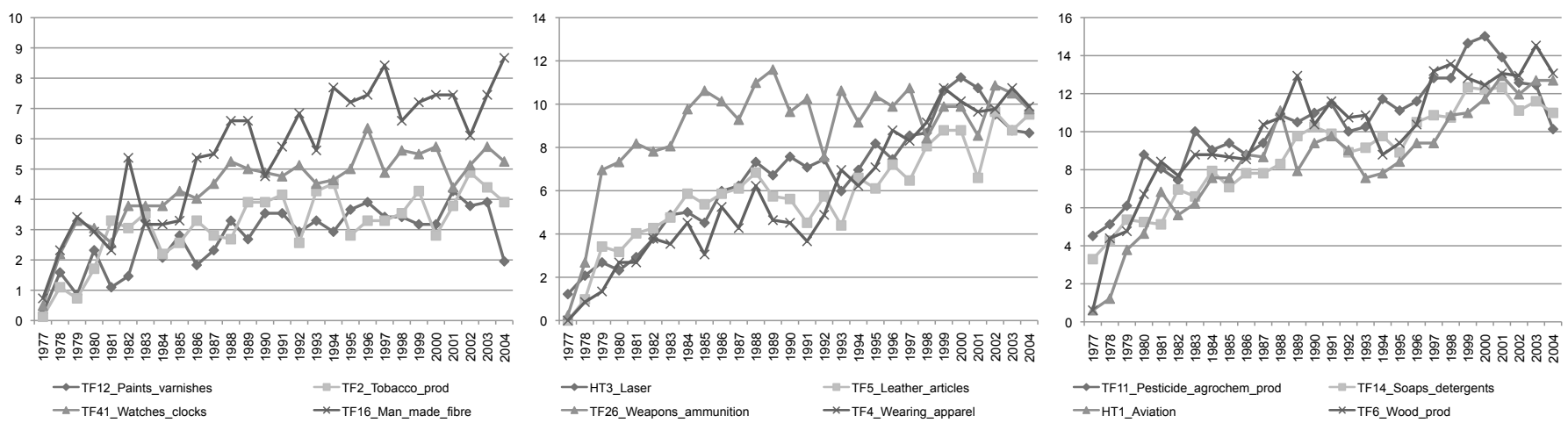

$\rightarrow$ TF11_Pesticide_agrochem_prod $\quad \rightarrow$ TF14_Soaps_detergents
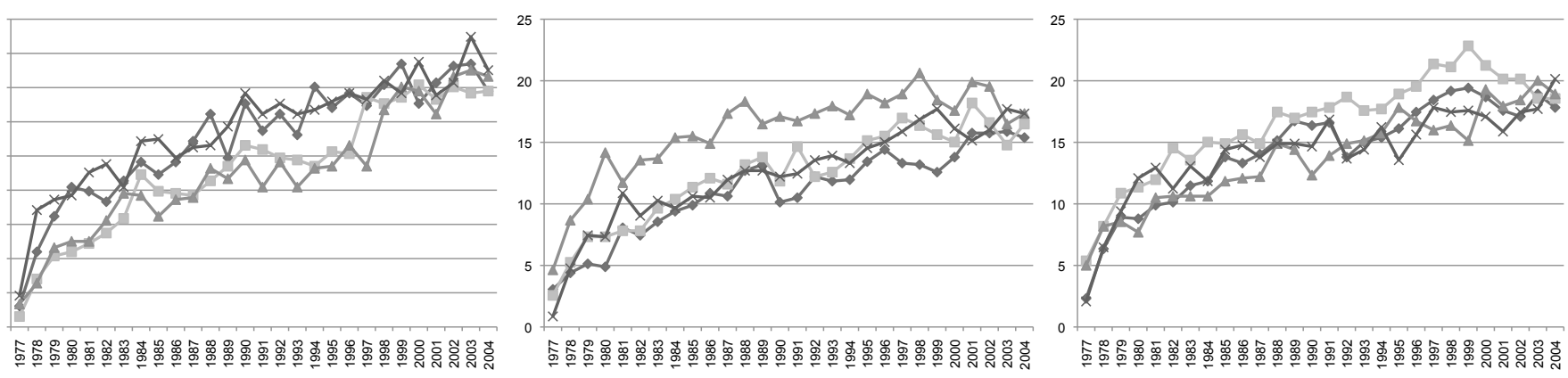

$\rightarrow-$ TF9_Petrol_prod_nucl_fuel $-\square-T F 32$ LLighting_equipment

\-TF31_Accumulators_battery $\quad$ *TF36_TV_radio_receiv_audio
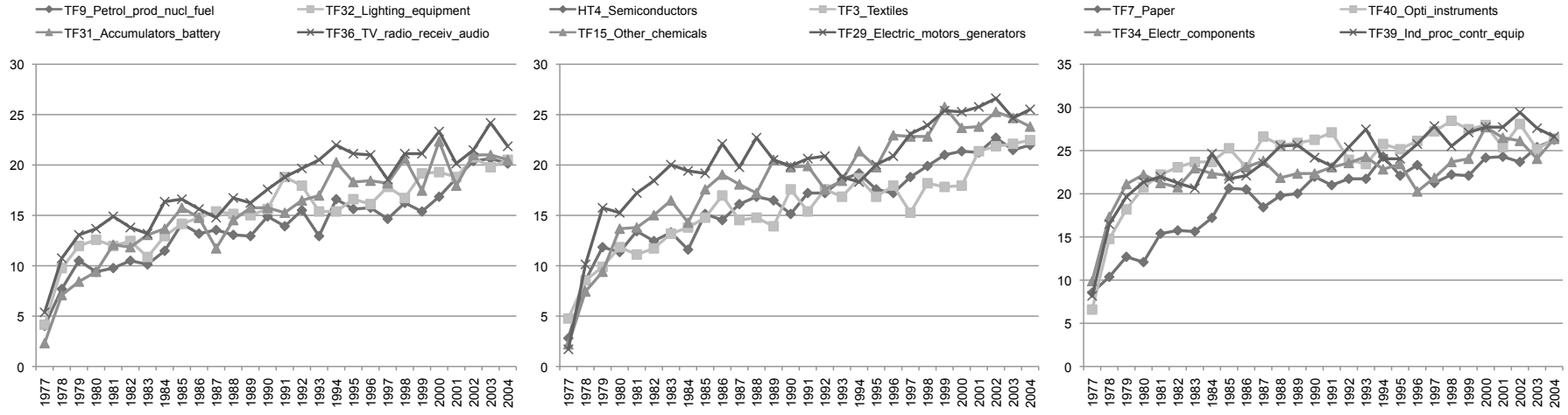

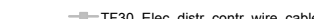
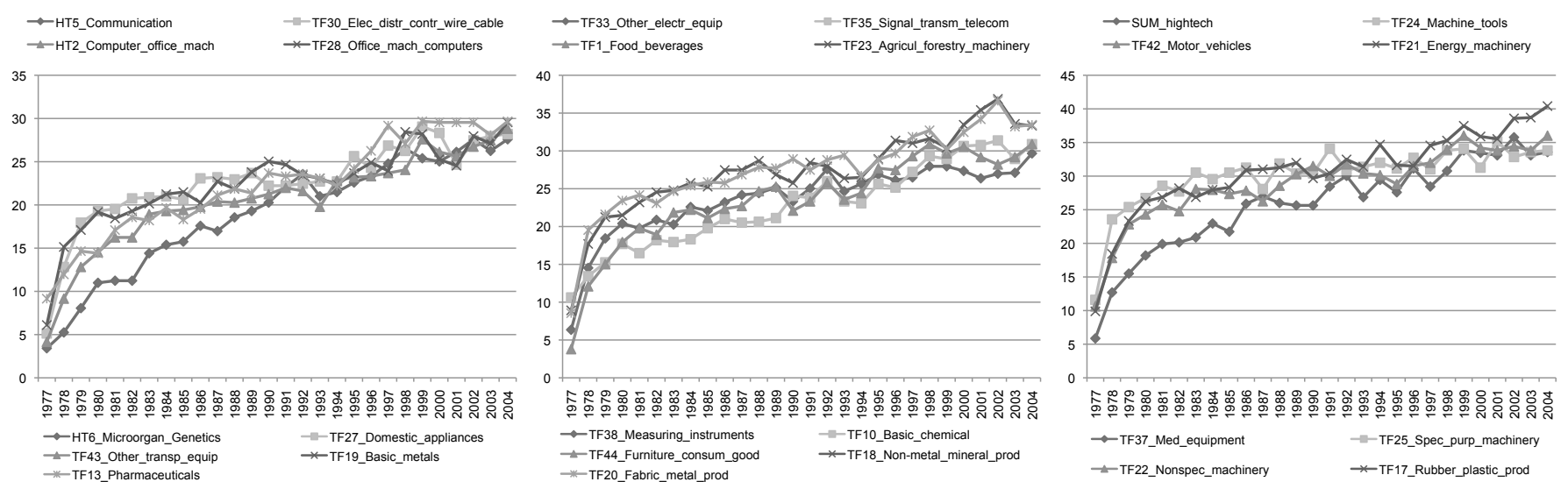

Source: own calculations and illustration. Notes: The sample covers 819 European TL3 micro regions. The patent data are generated by mySQL RegPAT (2009) database extractions and application of the ISI-SPRU-OST concordance. TL3 population data for the period 1988-2004 are constructed from EUROSTAT REGIO, OECD, ESPON and BBR data. For Belgium, Greece and the Netherlands, the OECD TL3 corresponds to the EUROSTAT NUTS2 level. For Germany, we make use of the

"Raumordnungsregionen". 
Figure 5: Share of Regions with LQ $>1$ of all Regions with $\mathrm{n}>0$ Patent Applications by Technology Field (1988-1990 vs. 2002-2004)

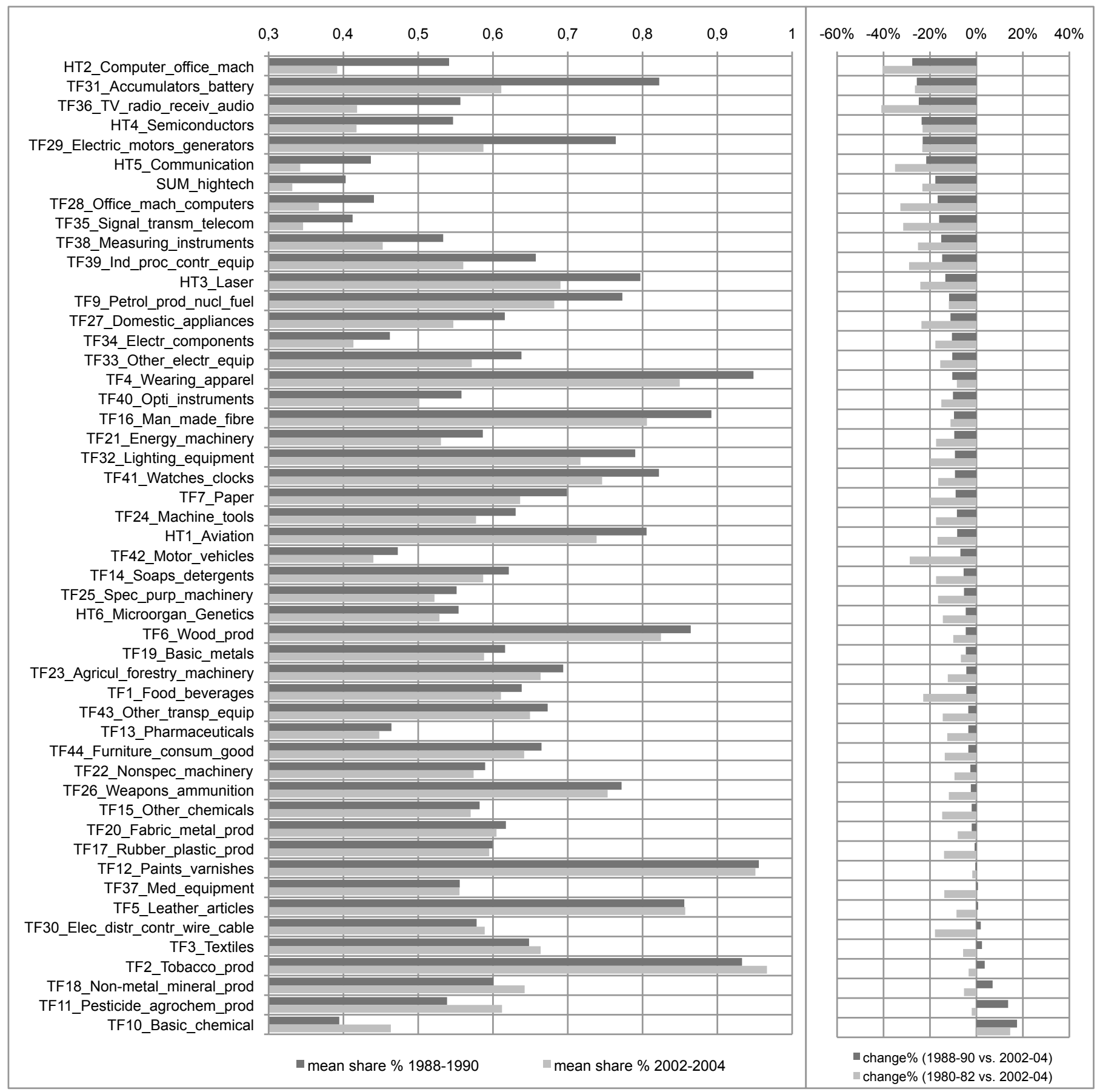

Source: own calculations and illustration. Notes: The sample covers 819 European TL3 micro regions. The patent data are generated by mySQL RegPAT (2009) database extractions and application of the ISI-SPRU-OST concordance. TL3 population data for the period 1988-2004 are constructed from EUROSTAT REGIO, OECD, ESPON and BBR data. For Belgium, Greece and the Netherlands, the OECD TL3 corresponds to the EUROSTAT NUTS2 level. For Germany, we make use of the "Raumordnungsregionen". 
Figure 6: Global Inequality Coefficients: Locational GINI $\left(G_{L O C}^{*}\right)$ of EPO Patent Applications by Technology Field
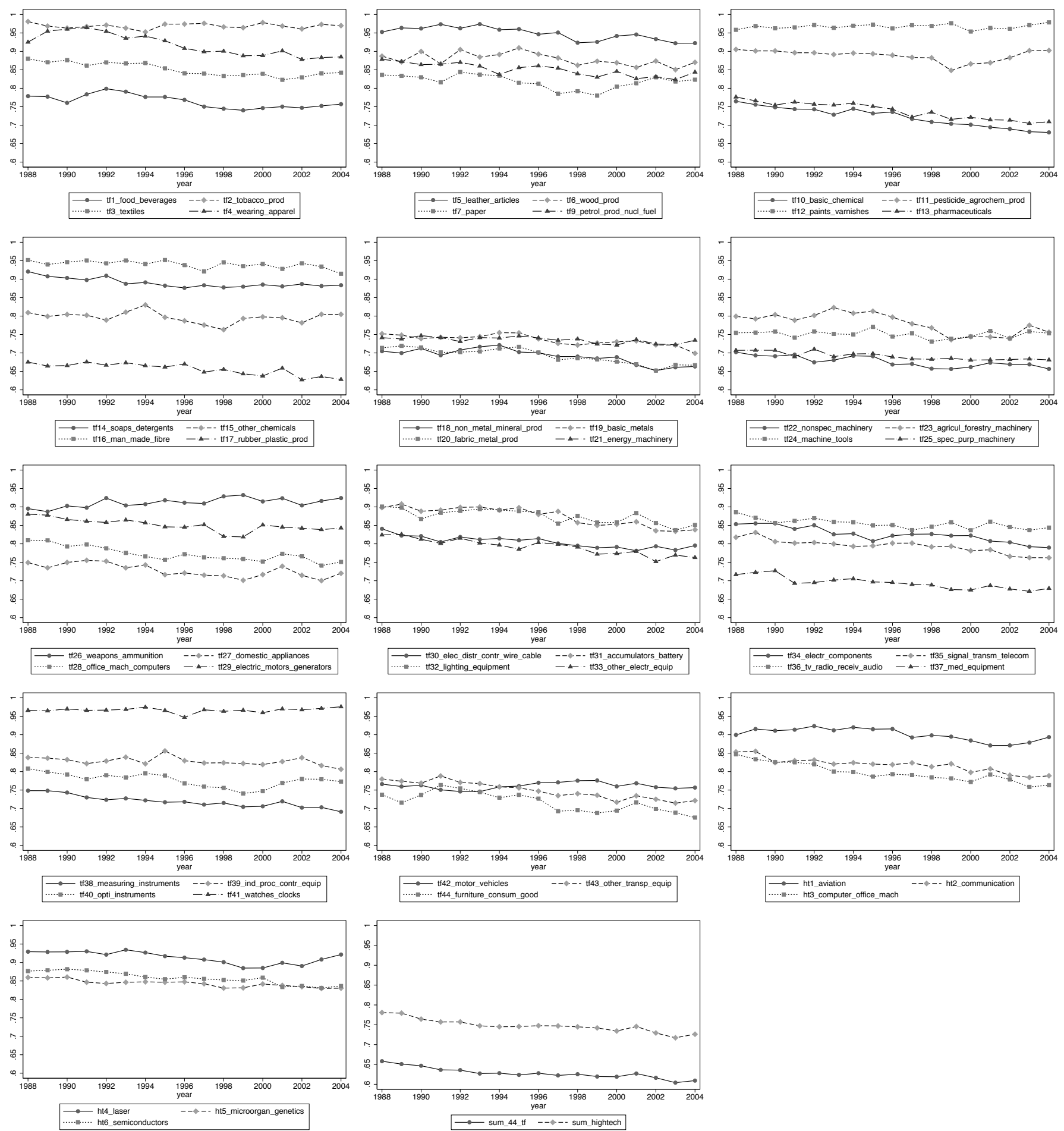

Source: own calculations and illustration. Notes: The sample covers 819 European TL3 micro regions. The patent data are generated by mySQL RegPAT (2009) database extractions and application of the ISI-SPRU-OST concordance. TL3 population data for the period 1988-2004 are constructed from EUROSTAT REGIO, OECD, ESPON and BBR data. For Belgium, Greece and the Netherlands, the OECD TL3 corresponds to the EUROSTAT NUTS2 level. For Germany, we make use of the "Raumordnungsregionen". 
Figure 7: Global Inequality Coefficients: Spatial GINI $\left(G_{S P A C E}^{*}\right)$ of EPO Patent Applications by Technology Field
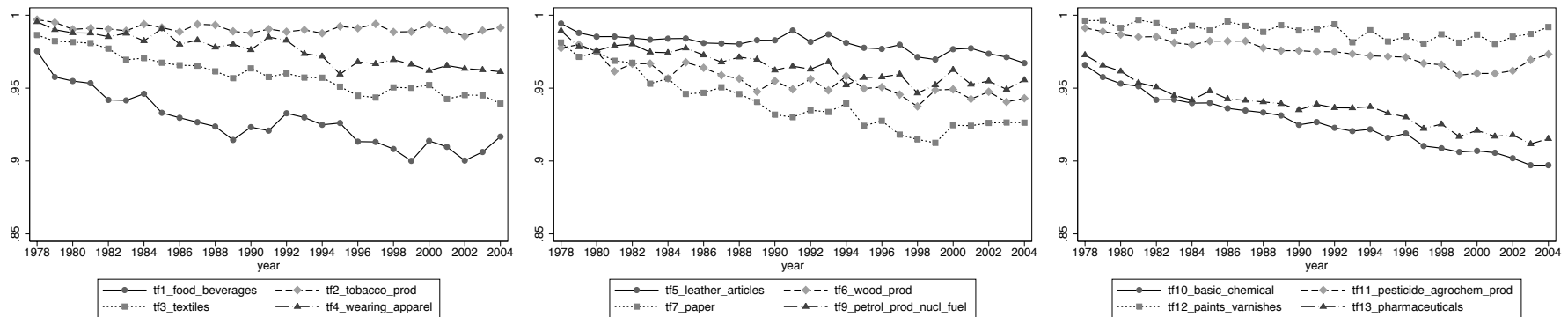
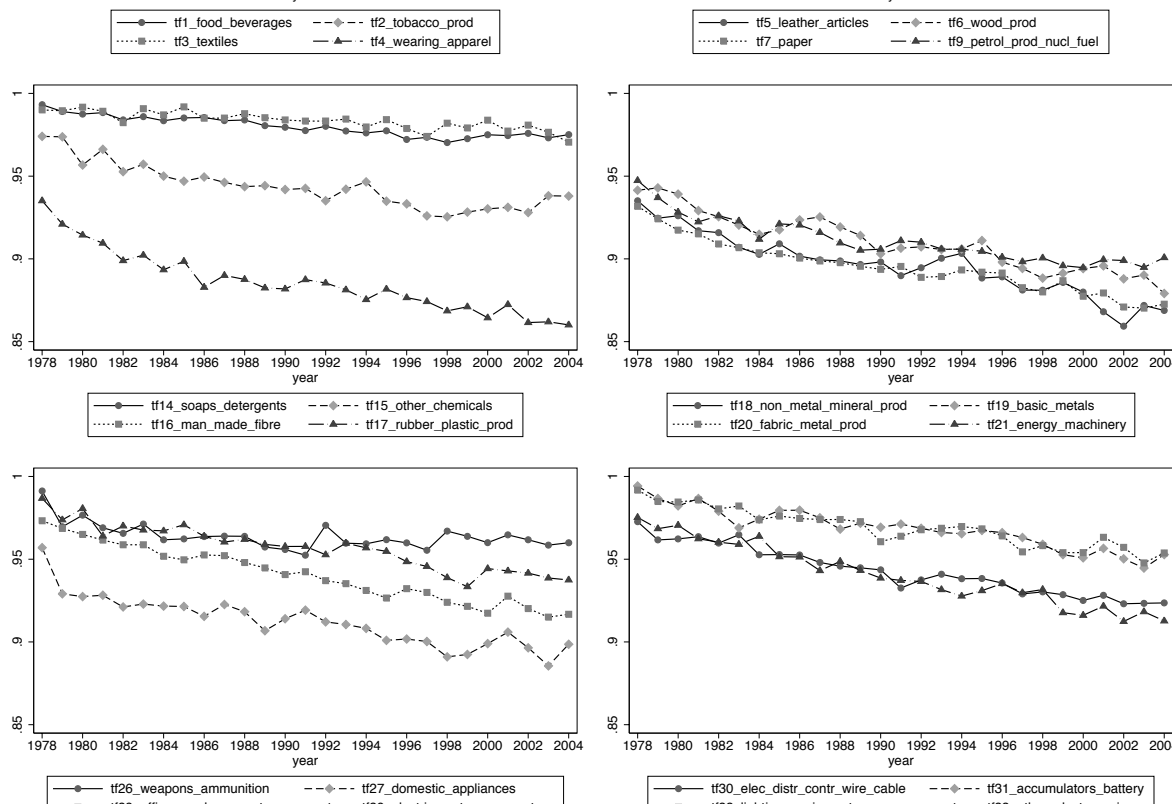

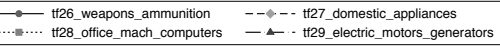
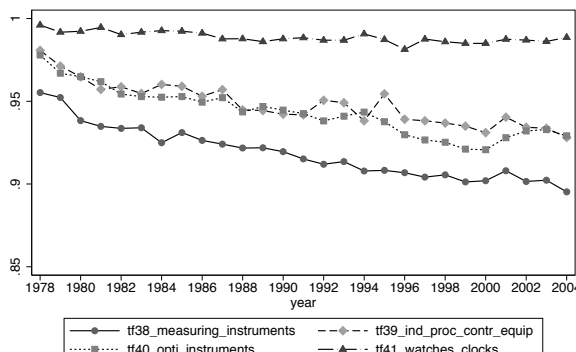

…-...... H38_measuring_inst

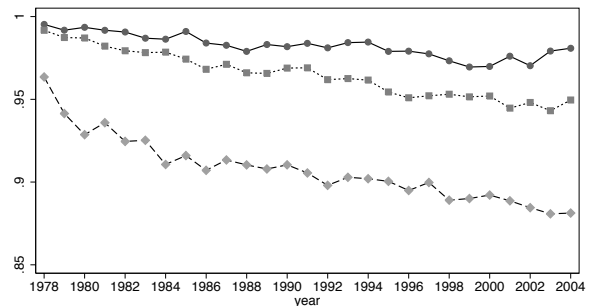

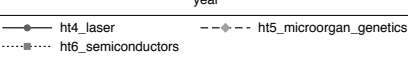
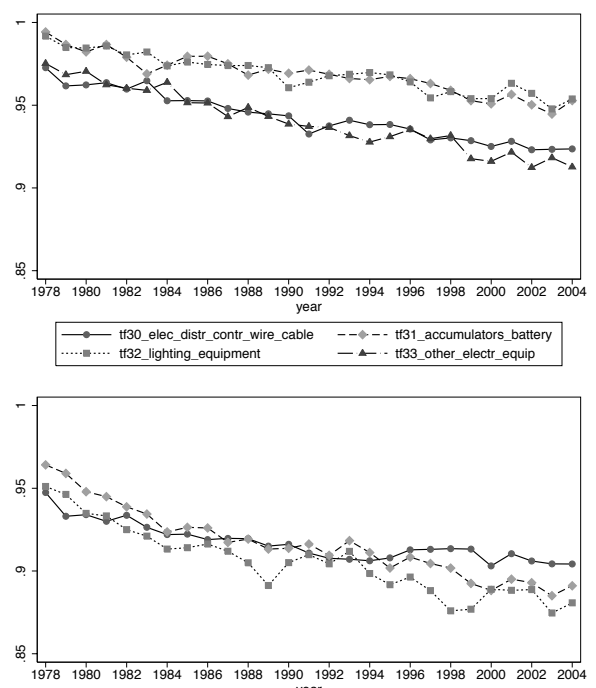

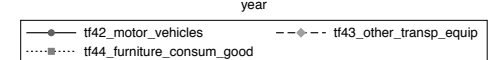

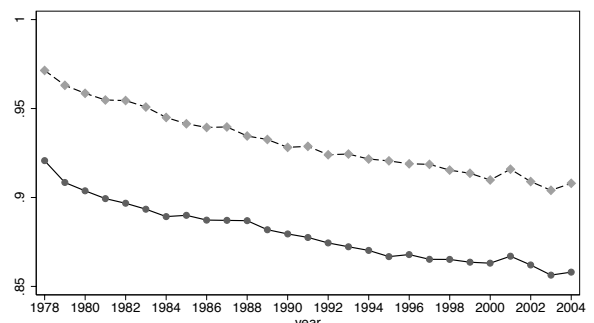

$\longrightarrow$ -

Source: own calculations and illustration. Notes: The sample covers 819 European TL3 micro regions. The patent data are generated by mySQL RegPAT (2009) database extractions and application of the ISI-SPRU-OST concordance. TL3 population data for the period 1988-2004 are constructed from EUROSTAT REGIO, OECD, ESPON and BBR data. For Belgium, Greece and the Netherlands, the OECD TL3 corresponds to the EUROSTAT NUTS2 level. For Germany, we make use of the

"Raumordnungsregionen". 
Figure 8: Global Inequality: Locational GINI $\left(G_{L O C}^{*}\right)$ Coefficient Dynamics by Technology Field (1988-1990 vs. 2002-2004)

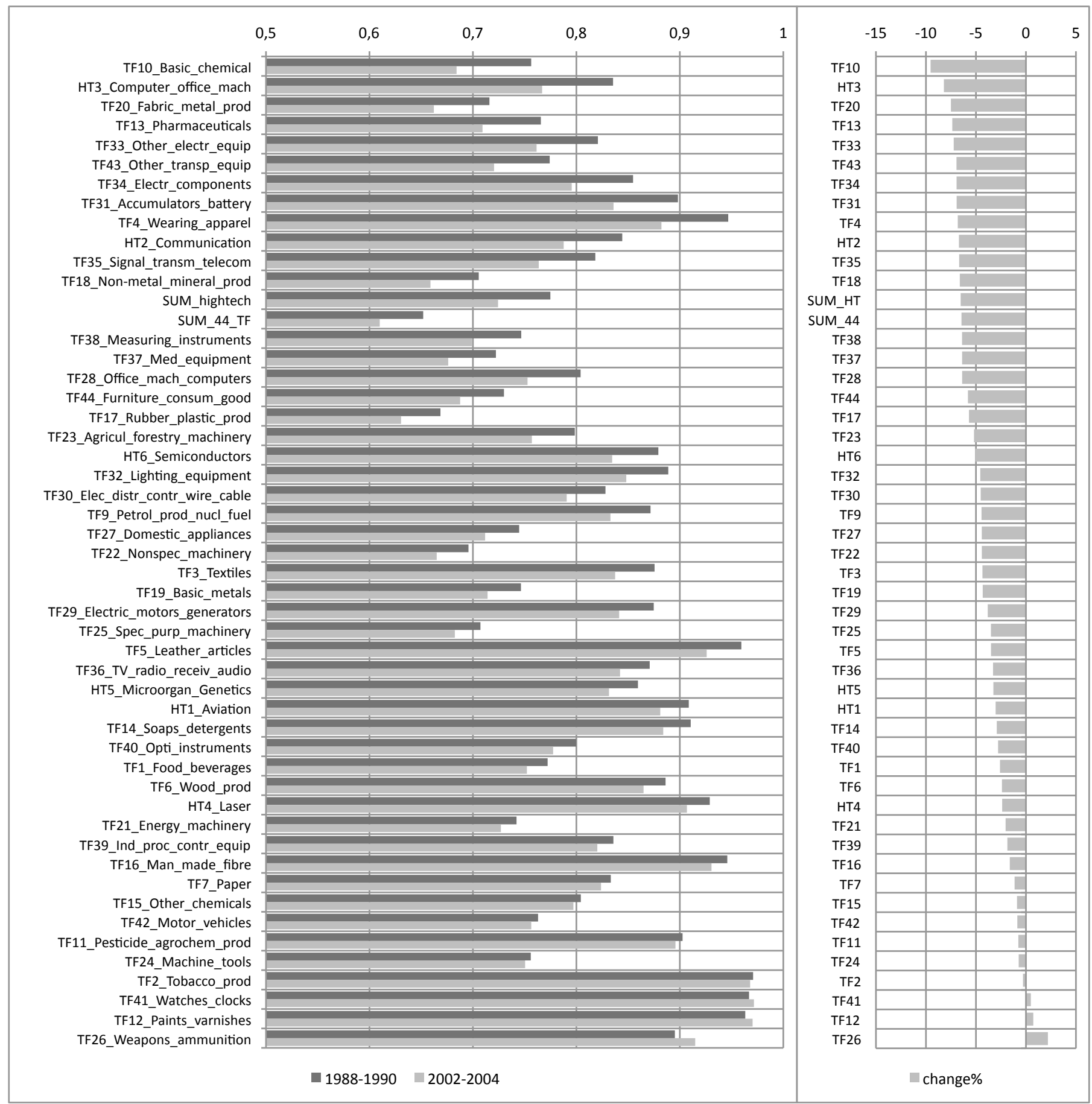

Source: own calculations and illustration. Notes: The sample covers 819 European TL3 micro regions. The patent data are generated by mySQL RegPAT (2009) database extractions and application of the ISI-SPRU-OST concordance. TL3 population data for the period 1988-2004 are constructed from EUROSTAT REGIO, OECD, ESPON and BBR data. For Belgium, Greece and the Netherlands, the OECD TL3 corresponds to the EUROSTAT NUTS2 level. For Germany, we make use of the "Raumordnungsregionen". 
Figure 9: Global Inequality: Spatial GINI $\left(G_{S P A C E}^{*}\right)$ Coefficient Dynamics by Technology Field (1988-1990 vs. 2002-2004)

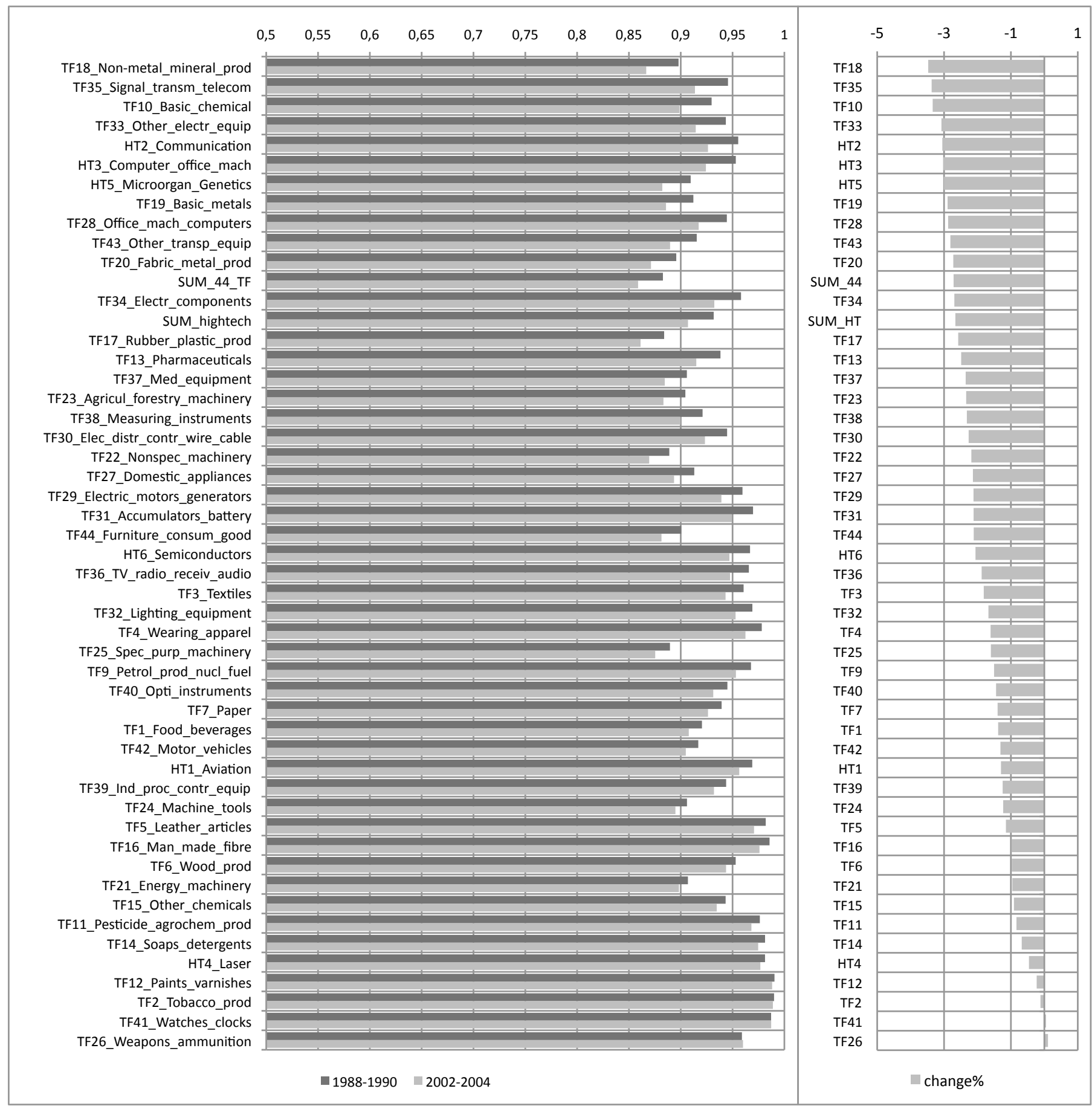

Source: own calculations and illustration. Notes: The sample covers 819 European TL3 micro regions. The patent data are generated by mySQL RegPAT (2009) database extractions and application of the ISI-SPRU-OST concordance. TL3 population data for the period 1988-2004 are constructed from EUROSTAT REGIO, OECD, ESPON and BBR data. For Belgium, Greece and the Netherlands, the OECD TL3 corresponds to the EUROSTAT NUTS2 level. For Germany, we make use of the "Raumordnungsregionen". 